\title{
Phylogenetic relationships based on morphological data and taxonomy of the genus Salvadora Baird \& Girard, 1853 (Reptilia, Colubridae)
}

\author{
Carlos A. HERNÁNDEZ-JIMÉNEZ ${ }^{1, *}$, Oscar FLORES-VILLELA ${ }^{\circledR 2}$, \\ Aranzazú AGUILAR-BREMAUNTZ ${ }^{3}$ \& Jonathan A. CAMPBELL ${ }^{4}$ \\ ${ }^{1,3}$ Facultad de Ciencias Biológicas, Benemérita Universidad Autónoma de Puebla, \\ Ave. San Claudio s/n, Edif. 112 Puebla, Puebla, Mexico, 72570. \\ ${ }^{1}$ Posgrado en Ciencias Biológicas, Universidad Nacional Autónoma de México, \\ Ciudad de México, Mexico, 04510. \\ ${ }^{1,2}$ Museo de Zoología, Facultad de Ciencias, Universidad Nacional Autónoma de México, \\ Ciudad de México, Mexico, 04510. \\ ${ }^{4}$ Department of Biology, The University of Texas at Arlington, Arlington, Texas 76019, USA. \\ *Corresponding author: acaltetepon22@gmail.com \\ 2Email: ofvq@unam.mx \\ ${ }^{3}$ Email: aikin.ab@gmail.com \\ 르ail: campbell@uta.edu \\ ${ }^{1}$ urn:1sid:zoobank.org:author:E5A769D1-7339-4C63-95FD-F259FBE30BF2 \\ ${ }^{2}$ urn:1sid:zoobank.org:author:9B2DCE3E-E832-4EBF-B04D-A18F15E58F73 \\ ${ }^{3}$ urn:lsid:zoobank.org:author:949926FB-9307-48E4-843C-8B80478D944D \\ ${ }^{4}$ urn:lsid:zoobank.org:author:443B36DB-F8A9-4C4A-85BB-7D95166FD14F
}

\begin{abstract}
The genus Salvadora has not been subjected to a modern phylogenetic analysis. Described in 1853, its taxonomic history is complex and confusing. In this study, we evaluate the monophyly of the genus and present the first phylogenetic hypothesis based on an analysis of 66 qualitative and quantitative morphological characters of over 1000 specimens representing all described taxa across their entire distribution. Morphological characters were processed in Fast Morphology for subsequent phylogenetic analysis in PAUP under the maximum parsimony criterion. We obtained a single tree in which Salvadora appears as a monophyletic group with two clearly defined geographic species groups: a southern mexicana group and a northern grahamiae group. Based on our phylogenetic hypothesis, we evaluate the taxonomic status of all described taxa. Additionally, we include a diagnosis for all species, distribution maps, and an illustrated dichotomous taxonomic key of the genus.
\end{abstract}

Keywords. Morphology, phylogeny, patch-nosed snakes.

Hernández-Jiménez C.A., Flores-Villela O., Aguilar-Bremauntz A. \& Campbell J.A. 2021. Phylogenetic relationships based on morphological data and taxonomy of the genus Salvadora Baird \& Girard, 1853 (Reptilia, Colubridae). European Journal of Taxonomy 764: 85-118. https://doi.org/10.5852/ejt.2021.764.1473

\section{Introduction}

The taxonomic history of the genus Salvadora Baird \& Girard, 1853 is rather intricate and convoluted. The genus was described by Baird \& Girard (1853), based on the type species Salvadora grahamiae. 
Jan \& Sordelli (1860) described S. bairdi, which was placed in the synonomy of $S$. grahamiae by Günther (1863) and Stejneger (1902). Smith (1938) re-evaluated the taxonomic status of S. grahamiae and $S$. bairdi and recognized them as two different species.

Cope (1861) proposed that the name of the genus be changed to Phimothyra because the name Salvadora had already been used by Linnaeus to describe a plant genus, but later withdrew his proposal because the emerging rules of nomenclature no longer required the use of different names for organisms belonging to different kingdoms. Under the name Phimothyra, Cope (1866) described P. hexalepis as a new species, though he himself later considered it to be a subspecies of $S$. grahamiae (Cope 1875). Stejneger (1902) noted differences between the two taxa and re-elevated $S$. hexalepis to species level. This nomenclature was used until Blanchard (1924) returned it to its previous status as a subspecies of S. grahamiae. Schmidt (1940) once again separated them into two separate species.

Günther (1863) recognized the affinity of a snake described as Zamenis mexicanus Duméril, Bibron \& Duméril, 1854 with Salvadora and placed it in the genus Salvadora. Later, Stuart (1932) placed the snake Masticophis pulcherrimus Cope, 1874 in the genus Salvadora.

In a monograph on the genus, Bogert (1939b) concluded that $S$. pulcherrima was limited to Central America and that the Mexican specimens formerly referred to as $S$. pulcherrima should be recognized as $S$. lemniscata (Cope, 1895) because of differences in the scutellation pattern (three preoculars in $S$. pulcherrima vs two in S. lemniscata), the color pattern (two longitudinal lines in S. pulcherrima vs four in S. lemniscata; black and white body color with a green head in S. pulcherrima, but olive and brown in S. lemniscata), and the number of maxillary teeth $(14-15+3$ in $S$. lemniscata vs $17+3$ in S. pulcherrima). Currently, S. pulcherrima is considered a synonym of Leptodrymus pulcherrimus because Bogert (1947) argued, based on a detailed morphological revision, that there were sufficient differences at the genus level and that S. pulcherima should be included in the genus Leptodrymus proposed by Amaral (1927).

Schmidt (1940) described Salvadora lineata and a new subspecies of S. hexalepis, S. h. deserticola. The following year, Smith (1941) described a new species, $S$. bogerti, and two subspecies of existing taxa, $S$. intermedia richardi and $S$. hexalepis celeris.

Bogert (1945) described two new subspecies of Salvadora hexalepis, S. h. klauberi and S. h. mojavensis, in addition to recognizing $S$. hexalepis virgultea and synonymizing $S$. h. celeris with $S$. h. deserticola.

Finally, Hernández-Jiménez et al. (2019) described a new species, Salvadora gymnorhachis, from the highlands of Central Oaxaca Mexico.

To date, nine species and eight subspecies have been described:

Salvadora Baird \& Girard, 1853

S. bairdi Jan in Jan \& Sordelli, 1860

S. bogerti Smith, 1941

S. deserticola Schmidt, 1940

S. grahamiae grahamiae Baird \& Girard, 1853

S. g. lineata Schmidt, 1940

S. gymnorhachis Hernández-Jiménez, Flores-Villela \& Campbell, 2019

S. hexalepis hexalepis (Cope, 1866)

S. h. mojavensis Bogert, 1945

S. h. klauberi Bogert, 1945

S. h. virgultea Bogert, 1935

S. intermedia intermedia Hartweg, 1940

S. i. richardi Smith, 1941

S. lemniscata (Cope, 1895)

S. mexicana (Duméril, Bibron \& Duméril, 1854) 
Recently, Flores-Villella (1993) and Wallach et al. (2014) listed the taxa of this genus without recognizing any subspecies.

In spite of being a fairly abundant and widespread group, the phylogenetic relationships within the genus have not been well studied. Pyron et al. (2011, 2013), Figueroa et al. (2016), Tonini et al. (2016), Zheng \& Wiens (2016) and Zaher et al. (2019) published molecular phylogenetic trees that include some species of Salvadora, but the results reported in those publications differ with regard to the monophyly of the group and the position of Salvadora with respect to relationships with other colubrid genera. None of those papers included all of the described taxa.

Recently, Hernández-Jiménez et al. (2019) published the description of a new species, Salvadora gymnorhachis. In that description, a phylogenetic hypothesis was proposed, based on a single molecular marker but not all described species in the genus were included (7 of 9). However, the hypothesis presented by Hernández-Jiménez et al. (2019) represents the most complete phylogenetic tree that has been proposed to date. In this phylogeny, Salvadora appears as a monophyletic group (Fig. 1).

There is no phylogenetic hypothesis for the relationships among the species of Salvadora based on morphological data and there is no recent analysis of the alpha taxonomy of the genus. While molecular systematics has proven to be a robust tool for the resolution of taxonomic problems, it is also evident that the use of morphological characters in phylogenetic reconstructions has been decreasing. Morphological characters have been shown to be useful in the reconstruction of phylogenetic relationships among many taxa (Jenner 2004; Wiens 2004; Smith \& Turner 2005). It is important that phylogenies representing hypotheses about the relationships among terminal taxa in a monophyletic group be supported by different lines of evidence.

Here, we provide an analysis of the alpha taxonomy of the genus and a phylogenetic hypothesis including all taxa described based on an examination of external morphology and dentition, as well as distribution maps and taxonomic keys.

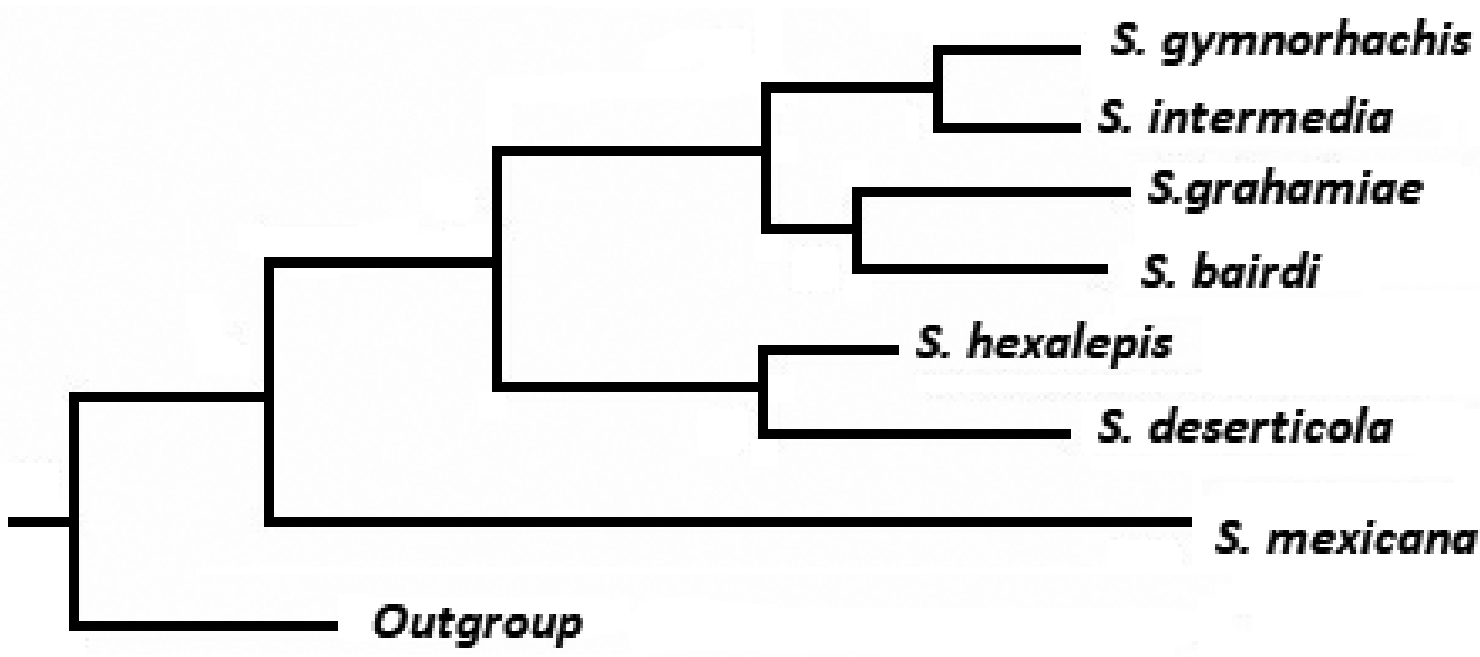

Fig. 1. Molecular phylogenetic tree modified from Hernández-Jiménez et al. (2019). 


\section{Material and methods}

Over 1000 specimens were examined from the following museums: Royal Ontario Museum (ROM), Mayborn Museum Baylor University (MMC), Museum of Vertebrate Zoology (MVZ), Monte L. Bean Life Science Museum, Brigham Young University (BYU), British Museum of Natural History (BMNH), California Academy of Sciences (CAS), Carnegie Museum (CM), University of Colorado Museum (UCM), Field Museum of Natural History (FMNH), Museum of Comparative Zoology, Harvard University (MCZ), University of Kansas, Museum of Natural History (KU), Natural History Museum of los Angeles (LACM), The Academy of Natural Sciences (ANSP), San Diego Society of Natural History (SDSNH), Texas Cooperative Wildlife Collection (TCWC), National Museum of Natural History, Smithsonian Institution (USNM), Florida Museum of Natural History (UF), University of Illinois, Museum of Natural History (UIMNH), University of Michigan, Museum of Natural History (UMMZ), University of New Mexico, Museum of Southwestern Biology (UNM), University of Texas at El Paso (UTEP), University of Texas at Arlington (UTA), American Museum of Natural History (AMNH), Museo de Zoología, Facultad de Ciencias, Universidad Nacional Autónoma de México (MZFC), Escuela de Biología Benemérita Universidad Autónomoa de Puebla (EBUAP) and Colección Nacional de Anfibios y Reptiles, Universidad Nacional Autónoma de México (CNAR) (acronyms follow Sabaj-Pérez 2016); collectively representing all taxa throughout the entire distributional range of the genus. The characters we used were similar to those described in previously published studies of the genus Salvadora (Bogert 1947) and Hernández-Jiménez et al. (2019).

Distribution maps were constructed with all museum records and specimens examined as well as available records in the recent literature, using Quantum GIS ver. 1.7 (QGIS 2012). Revised diagnoses and dichotomous keys were prepared for each taxon.

Three hundred and sixty-one specimens were selected, representing all of the known populations of each taxon (including type or topotypic material for the species and subspecies), since the specimens selected represent all of the variation that we recorded. A detailed analysis of 64 qualitative scale, color pattern and meristic and morphometric characters (Supp. file 1) were used to reconstruct a phylogenetic hypothesis. Salvadora bogerti and Salvadora intermedia richardi were not included in the reconstruction of the phylogenetic hypothesis because we consider $S$. bogerti to be a synonym of $S$. bairdi and S. i. richardi as a junior synonym of $S$. intermedia (see comments in the Results section).

Given that some of the morphological characters analyzed varied within the terminal taxa (polymorphic characters), they were coded as follows: morphometric and meristic characters were coded using the gap-weighting method proposed by Thiele (1993), while for qualitative characters each character state was treated as an independent character and coded as a binary present-absent character (Wilkinson 1995).

The raw data matrix was processed in Fast Morphology ver. 1.0 (Chang \& Smith 2001), which transforms the character state into a code that can be used in a parsimony analysis and obtains the frequency of subcharacters using the Generalized Frequency Coding (GFC) technique proposed by Smith \& Gutberlet (2001).

The phylogenetic analysis was run in PAUP, ver. 4.0a147 (Swofford 2002), under the maximum parsimony criterion using a heuristic search and the TBR branch exchange algorithm with 1000 replicates adding taxa randomly. A Bootstrap analysis with 1000 pseudoreplicates was then run. As outgroups, the following species of snakes were used: Masticophis mentovarius Duméril Bibron \& Dumeril, 1854, Drymarchon melanurus Duméril Bibron \& Dumeril, 1854, Drymobius margaritiferus Schlegel, 1837, Leptophis mexicanus Duméril Bibron \& Dumeril, 1854 and Leptodrymus pulcherrimus Cope, 1874, according to previously published studies by Amaral (1927), Bogert (1947), Pyron et al. (2011, 2013), and Hernández-Jiménez et al. (2019). 


\section{Results}

\section{Phylogenetic relationships}

A single tree with a length of 584837 steps was obtained from the heuristic search under the parsimony criterion (Fig. 2). The group made up of all the species and subspecies of the genus appears as a monophyletic group with a Bootstrap value of 100 . Within the group, there are two clearly defined clades with high Bootstrap values, one with $S$. mexicana and $S$. lemniscata with a Bootstrap value of 100 (mexicana group) and the other with the remaining species and subspecies, also with a Bootstrap

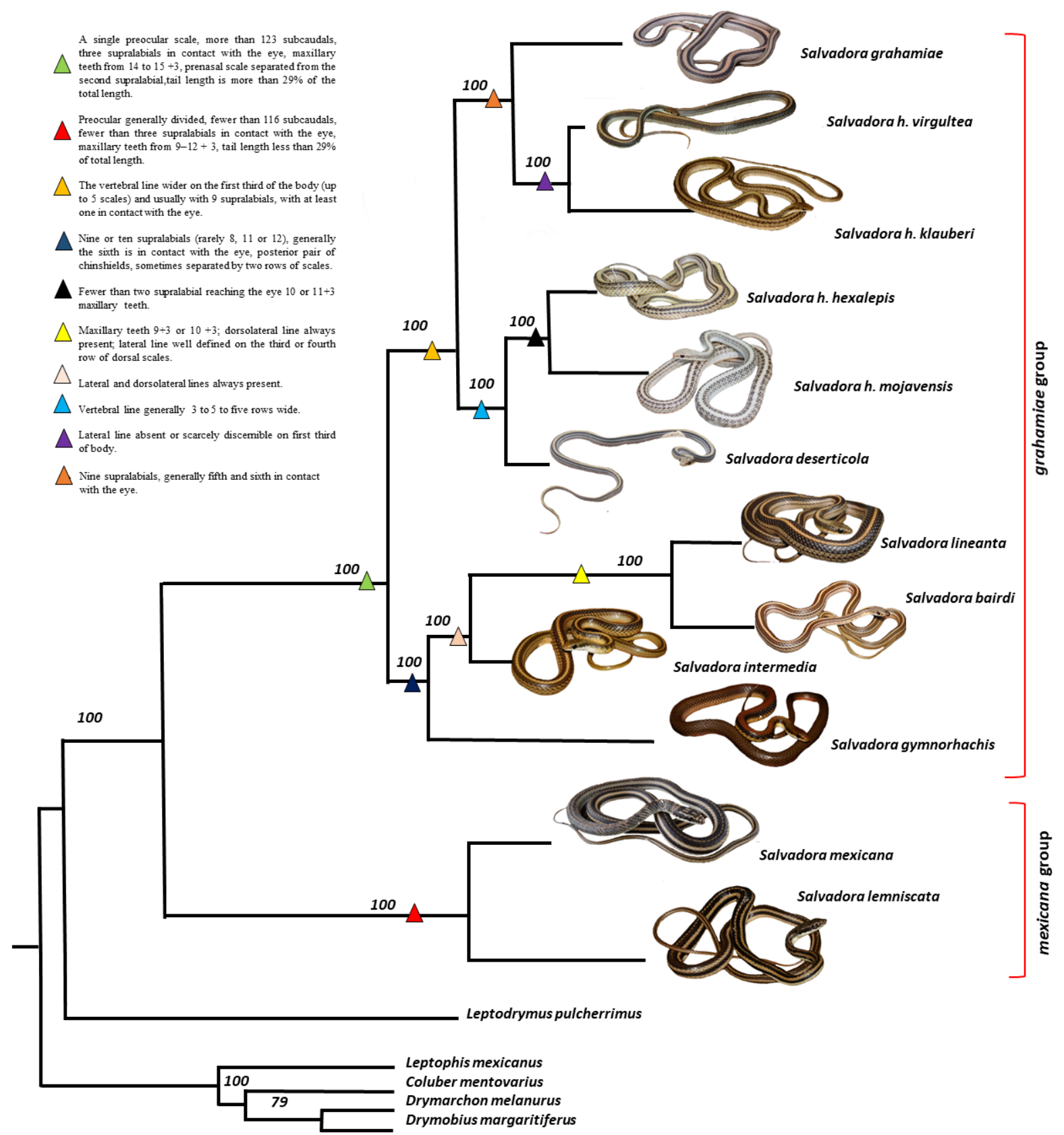

Fig. 2. Tree obtained based on a heuristic search under the parsimony criterion, with a length of 584837 steps, a consistency index (CI) of 0.8297 and a retention index (RI) of 0.8276 ; numbers over the nodes represent the Bootstrap values. 
value of 100 (grahamiae group). Within the second group there are two subgroups. The first contains Salvadora deserticola, the four subspecies of Salvadora hexalepis, and Salvadora grahamiae with high Bootstrap values. The second group contains Salvadora bairdi as a sister group to Salvadora lineata with a Bootstrap value of 100, also grouped with Salvadora intermedia with a Bootstrap value of 100 and includes the most recently described species in the genus, Salvadora gymnorhachis.

The monophyly of the genus is supported as all the species have an enlarged rostral scale interceding between the internasals that sometimes has free edges. The two large groups, in which the species and subspecies of Salvadora are found, are clearly differentiated by the number of subcaudal scales, the number of maxillary teeth, and the shape of the preocular scale. The mexicana group includes the two largest species of the genus Salvadora, S. lemniscata and $S$. mexicana, while the second group, grahamiae, includes all the other species and subspecies of the genus.

\section{Taxonomy}

Class Reptilia Laurenti, 1768

Order Squamata Oppel, 1811

Family Colubridae Oppel, 1811

Genus Salvadora Baird \& Girard, 1853

Salvadora Baird \& Girard, 1853: 104-105.

Phimothyra Cope, 1861: 566.

\section{Type species}

Salvadora grahamiae Baird \& Girard, 1853.

\section{Diagnosis}

Usually nine-plate supracephalic scaling on the head; enlarged rostral scale that intercedes between the internasals and sometimes has free edges; two nasal scales; preoculars and postoculars present; loreal scale simple or divided; smooth body scales sometimes with two apical pits; 17 rows of scales around the body on the anterior third of body and midbody; cloacal scale divided; subcaudal scales in two series; elongated head; large eyes; round pupil; long tail. Hemipenis simple with spines at the base, replaced midway by calyces that cover half the length of each organ: sulcus simple with a long basal spine. Normally from 9 to 15 maxillary teeth followed by a diastema and three enlarged teeth $(9-15+3)$. Color pattern consisting of two longitudinal, dorsolateral and lateral lines on each side of the body and a pale vertebral line generally present.

\section{Etymology}

Derived from the Latin 'salvator', which means 'savior', and 'adora', which means 'honor', an explicit homage to the collector of the type species S. grahamiae, Col. J.D. Graham.

\section{Distribution}

Southern United States from southern California, western Nevada, Utah, to Arizona, New Mexico, to central Texas; in Mexico, the Baja California Peninsula and Sonora south to the lowlands of Chiapas and Guatemala excluding the Yucatán Peninsula.

\section{Remarks}

The phylogenetic hypothesis and the character revision reveal that there are two groups within the genus, as previously suggested by Smith $(1938,1941)$ : mexicana and grahamiae. 


\section{The mexicana group}

The two species in this group are defined by several synapomorphies: a single preocular scale, more than 123 subcaudal scales, three supralabials in contact with the eye, maxillary teeth from 14 to $15+3$, prenasal scale separated from the second supralabial, and the tail length is more than $29 \%$ of the total length.

Salvadora lemniscata (Cope, 1895)

Fig. 3

Drymobius lemniscatus Cope, 1895: 203.

Drymobius (Eudryas) pulcherrimus Bocourt 1890: 725-726.

Salvadora lemniscata - Bogert 1939b: 142.

\section{Diagnosis}

Rostral slightly elongated and projecting toward the back; 9 supralabials, 3 supralabials in contact with the eye, the fourth, fifth and sixth; generally 12 infralabials, sometimes 11 or 13; single preocular; single loreal; prenasal separated from the second supralabial; a second pair of chinshields larger than the first one in contact with each other or separated by a row of scales; 194-206 ventrals; $128-141$ subcaudals; tail is 29 to $34 \%$ of total length; $14-15+3$ maxillary teeth. Color pattern consists of a pale vertebral line extending from the parietal region, and is three rows wide on the first third of the body and one row wide on the rest of the body, flanked by a pair of dark dorsolateral lines two to four scales wide, interrupted at the neck without touching the head; two dark lateral lines, sometimes slightly interrupted in the neck region or continuing toward the sides of the head, passing by the eyes to the nasal scales.

Differs from the other species in the genus by having more maxillary teeth $(14-15+3)$; a single preocular scale; tail length 29 to $34 \%$ of total length; 4 longitudinal lines along the body, dorsolaterals interrupted on the neck region; 194 to 206 ventral scales.

\section{Etymology}

The species name comes from the Latin 'lemniscatus', which means 'adorned with bands', doubtless in reference to the stripes along its body.

\section{Type material}

MEXICO - "Mexique occidental" [Western Mexico], locality uncertain, probably from Tehuantepec, Oaxaca; F. Sumichrast leg.; MNHN 1891.0260.

\section{Distribution and conservation}

From Acapulco in the state of Guerrero southward the Pacific coast, across the Isthmus of Tehuantepec to the coast of Chiapas, the Central Depression of the Grijalva River, and Huehuetenango, Guatemala (Fig. 3).

Within its distribution it occurs in at least two protected natural areas. Mexican legislation has listed this species as subject to Special Protection and the IUCN has it listed as a species of Least Concern.

\section{Remarks}

Three additional specimens examined (UTA 45840 Guatemala: Huehuetenango, $2.4 \mathrm{~km}$ from Nenton on Road to la Trinidad; UTA 45842 Guatemala: Huehuetenango, $0.3 \mathrm{~km}$ S Cuatro caminos, La DemocraciaNenton Road; UTA 45843 Guatemala Nenton, Hacienda Miramar, La Fortuna near Pozo) represent the first records of Salvadora lemniscata for Guatemala. 


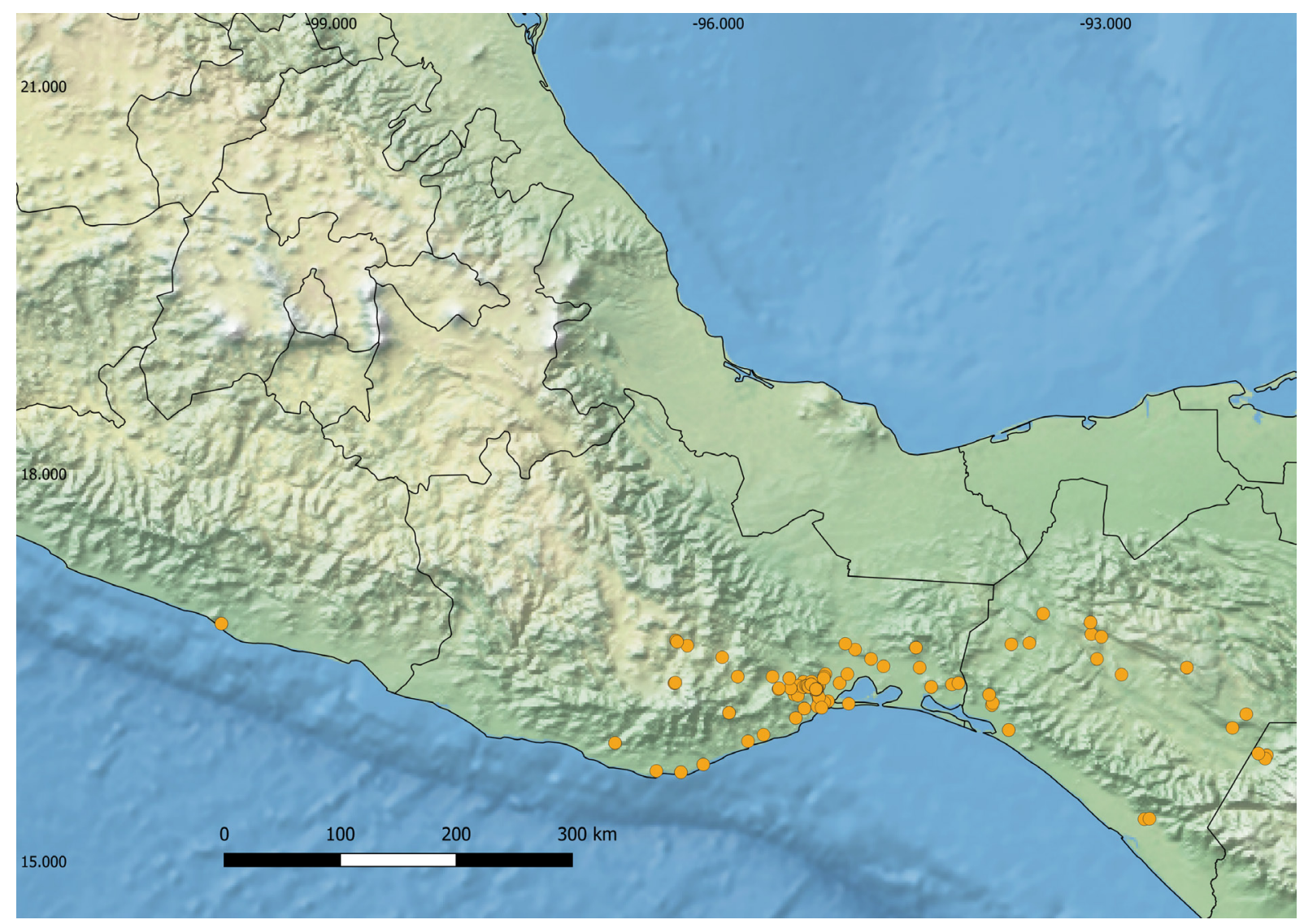

Fig. 3. Locality records of Salvadora lemniscata (Cope, 1895).

Salvadora mexicana (Duméril, Bibron \& Duméril, 1854)

Fig. 4

Zamenis mexicanus Duméril, Bibron \& Duméril, 1854: 695-696.

Salvadora mexicana - Günther 1863: 349.

\section{Diagnosis}

Rostral elongated; 9 supralabials, 3 supralabials in contact with the eye, the fourth, fifth and sixth; $10-11$ infralabials; a single preocular; a single loreal scale; prenasal in contact with the second supralabial; a second pair of chinshields in contact with each other or separated by a row of scales; 182-197 ventrals; 125-145 subcaudals; tail length is 31 to $42 \%$ of total length; $15+3$ maxillary teeth. Color pattern on the first third of the body consists of mottled transverse patches becoming transverse bars on the neck; the back of the head is dark with pale longitudinal patch in the center; the rest of the body has pale vertebral line flanked by two dark dorsolateral lines; and two dark lateral lines.

This species differs from its congeners by having a single preocular scale; tail length is approximately one third of the total length (31-42\%); and by having four dark longitudinal lines interrupted on the first third of the body where they are replaced by transverse bands or patches. 


\section{Etymology}

Patronym referring to the country of origin.

\section{Type material}

MEXICO • "Cap Corrientes, Mexique” [Jalisco, Cabo Corrientes]; MNHN 3585.

\section{Distribution and conservation}

Endemic to Mexico. Occurs from Nayarit southward on the Pacific coast in the states of Nayarit, Jalisco, Colima, Michoacán, Guerrero, and Oaxaca entering the Balsas River Basin, toward central Guerrero, the states of Estado de México, Morelos and southwestern Puebla (Fig. 4).

Within its distribution it is found in at least four protected natural areas. Mexican legislation has listed this species as subject to Special Protection and the IUCN has it listed as a species of Least Concern.

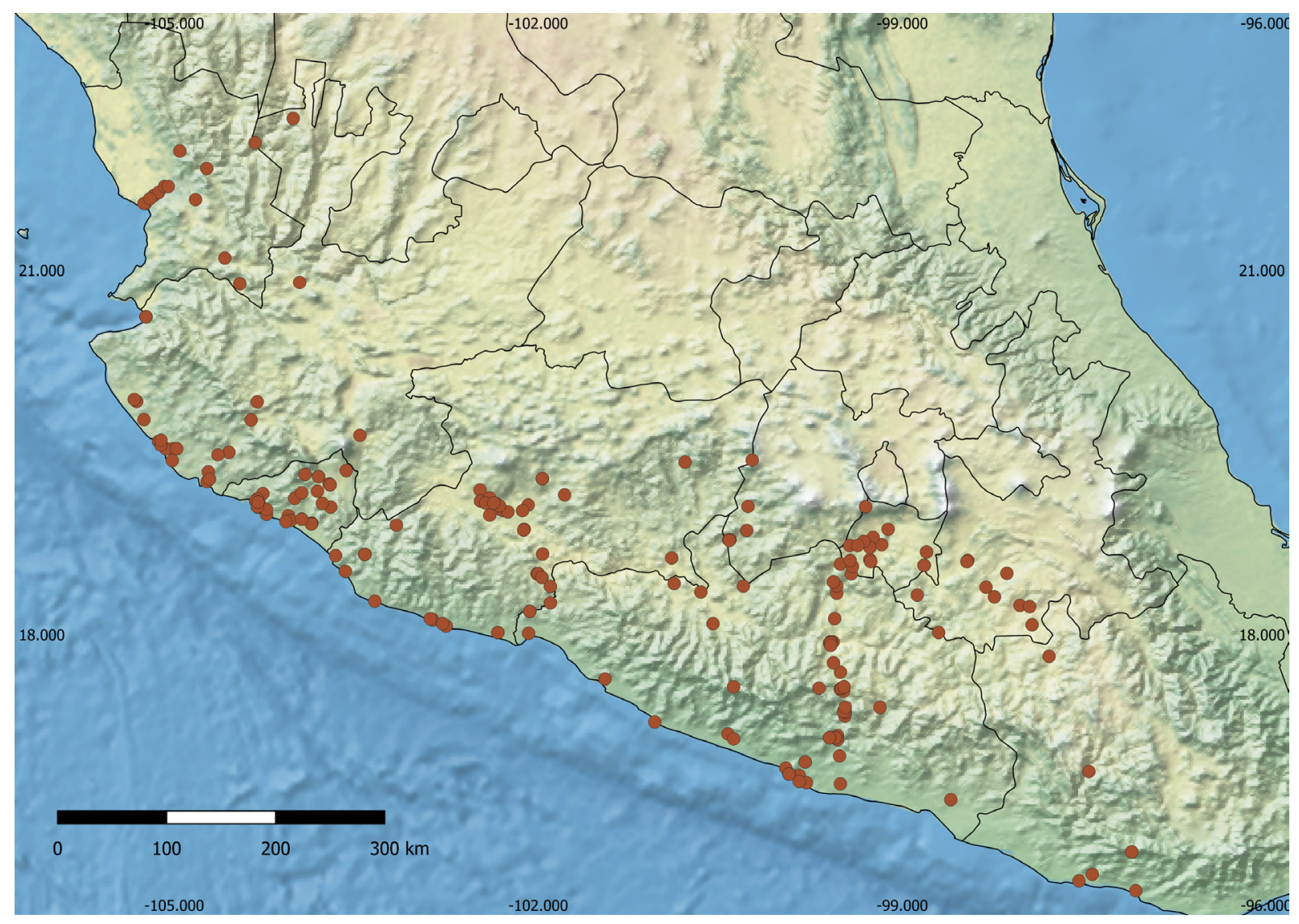

Fig. 4. Locality records of Salvadora mexicana (Duméril, Bibron \& Duméril, 1854). 


\section{The grahamiae group}

The taxa in this group are defined by several synapomorphies, including preocular generally divided; fewer than 116 subcaudals, normally fewer than three supralabials in contact with the eye, maxillary teeth from 9 to $12+3$; tail length less than $29 \%$ of total length.

\section{Salvadora bairdi Jan in Jan \& Sordelli 1860}

Fig. 5

Salvadora bairdi Jan in Jan \& Sordelli, 1860: pl. 3 fig. 2.

Salvadora bogerti Smith, 1941: 2-6.

\section{Diagnosis}

Rostral without free edges, slightly elongated towards the back interceding between internasals; 8 supralabials, generally fourth and fifth touching the lower edge of the eye; 10 infralabials; preocular divided; a single loreal; prenasal may or may not be in contact with the second supralabial; a second pair of chinshields in contact with each other or sometimes separated by a row of scales;175-209 ventrals; $82-108$ subcaudals; tail length 22 to $29 \%$ of the total length; maxillary teeth normally $9+3$. Color pattern consists of a pale vertebral line three scales wide that begins on the neck and tapers to one scale wide on the last third of body; two pairs of dark longitudinal lines, dorsolateral lines two to four scales wide not touching the temporal region and connecting on the anterior part, forming a patch that separates them from the parietal region; lateral lines involving the third row of dorsal scales and may or may not be interrupted by an irregular pattern of patches in the posterior region of head.

This species differs from its congeners by having a single loreal, edges of rostral scale not free, maxillary teeth $9+3$, and a pale vertebral line that extends to the neck without touching the temporal region.

\section{Etymology}

Named in honor of Spencer Fullerton Baird.

\section{Type material}

MEXICO • holotype of Salvadora bogerti; “Tehuantepec”, locality uncertain; USNM 30296.

MEXICO • holotype of Salvadora bairdi; "Méxique" Guanajuato, restricted to Acámbaro, see Smith \& Taylor (1950); Museo Civico di Storia Naturale di Milano, Westphal coll.; MSNM (destroyed).

\section{Distribution and conservation}

Endemic to Mexico; distributed from Sonora and Chihuahua southward through the states of Sinaloa, Durango, Zacatecas, Nayarit, Jalisco; in central Mexico through the Trans-Mexican Volcanic Belt in the states of Querétaro, Guanajuato, Michoacán, Guerrero, Estado de México, Hidalgo, Morelos, Puebla, and Veracruz (Fig. 5).

Within its distribution, it is found in at least four protected natural areas. Mexican legislation has listed this species as subject to Special Protection and the IUCN has it listed as a species of Least Concern.

\section{Remarks}

The holotype of $S$. bogerti is a juvenile purportedly collected by F. Sumichrast in the vicinity of "Tehuantepec"; this locality does not appear to be the usual collecting site of Tehuantepec, Oaxaca, but rather a community in the municipality of San Andrés Tuxtla called Tehuantepec (from the notes of C.M. 


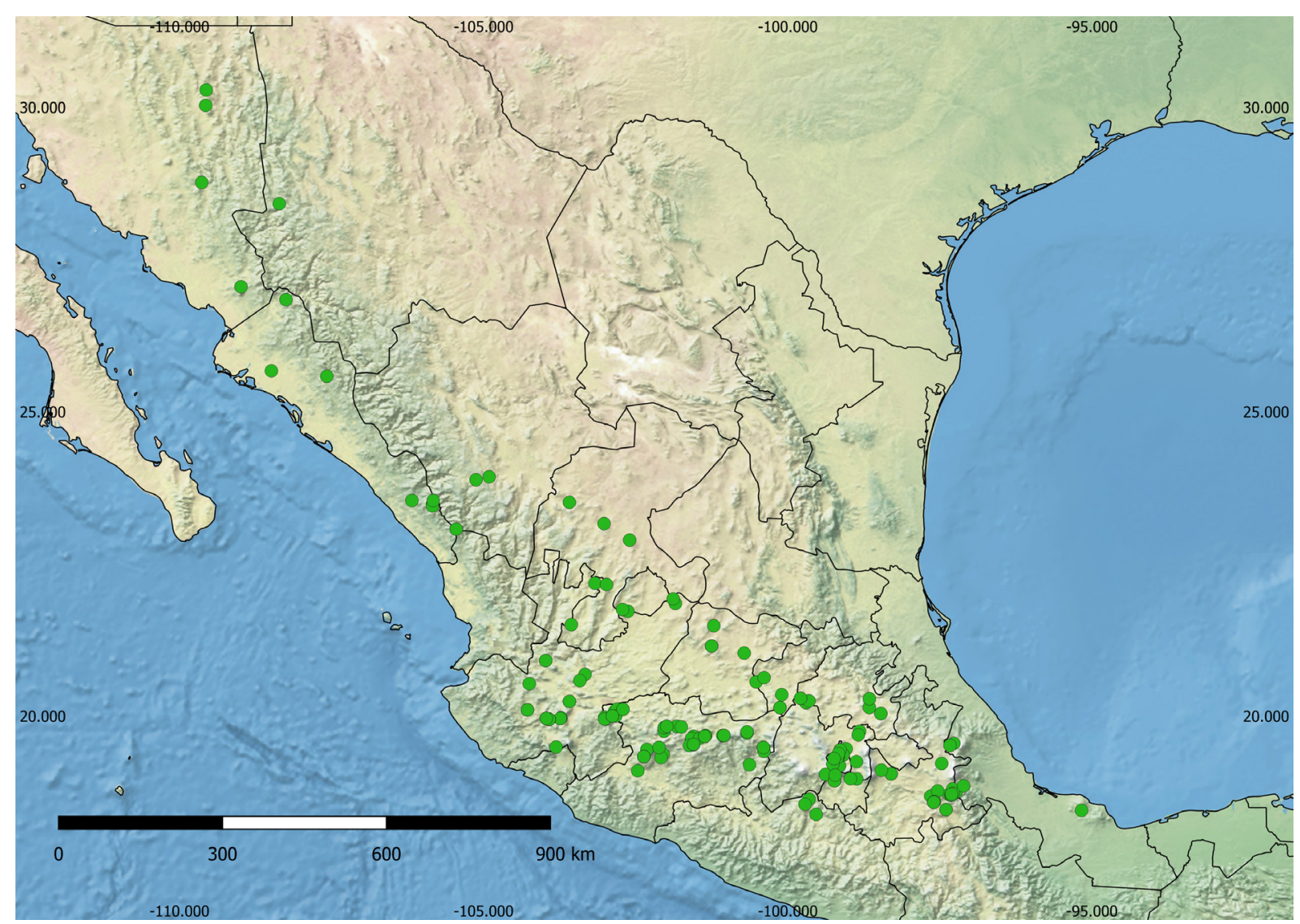

Fig. 5. Locality records of Salvadora bairdi Jan \& Sordelli, 1860.

Bogert; Pérez-Higareda \& Smith 1991). Independently of this, the morphological characteristics of the holotype of bogerti correspond with the morphological characteristics of a population of specimens of Salvadora bairdi collected in the state of Veracruz, near Cordoba. It is worth mentioning that Salvadora bairdi is the species that varies the most in squamation and coloration patterns. After an extensive review of the literature and after many years of collecting (either personal or by other collectors) in the region of Los Tuxtlas, no more specimens have come to light, and it is apparent that the holotype of S. bogerti may have been a mislabeled specimen. Pérez-Higareda et al. (2007) do not list this species as part of the ophidiofauna of the region; therefore, we conclude that the locality of the type of Salvadora bogerti is not from Los Tuxtlas and more likely was collected by Sumichrast near Orizaba; a locality where he lived and made collections.

Some individuals in northern Sinaloa, southern Sonora and Chihuahua have a series of patches or transverse patches on the first third of body; however, in spite of being an isolated population, this character is not constant in the specimens we examined.

\section{Salvadora deserticola Schmidt 1940}

Fig. 6

Salvadora hexalepis deserticola Schmidt, 1940: 146, fig. 14.

Salvadora hexalepis celeris Smith, 1941: 9, fig. 6. 


\section{Diagnosis}

Rostral scale well developed, elongated and with free edges; 9 supralabials, two or rarely three in contact with the eye (generally the fifth and sixth in contact); 11 infralabials; preocular scale divided; a single loreal; prenasal in contact with the second supralabial; a second pair of chinshields separated by two rows of scales; $180-205$ ventrals; $66-87$ subcaudals; tail is 19 to $23.5 \%$ of the total length; maxillary teeth normally $11+3$. Color pattern consists of a pale vertebral stripe, five scales wide on the anterior third of the body and three scales wide on the rest of the body, flanked by a pair of dark dorsolateral lines located on the sixth and seventh row and separated from the lateral lines by at least one row of scales; lateral lines begin on the fourth row or on the margins of the third and fourth rows of dorsal scales. Lateral and dorsolateral lines fused on the neck.

Differs from the other species in the genus by having a single loreal, usually not divided; tail shorter (less than $24 \%$ of the total length) and fewer subcaudal scales.

\section{Etymology}

The species name is derived from the Latin words 'desertum', which means 'desert', and 'icola', which means 'inhabitant', in reference to the habitat at the type locality.

\section{Type material examined}

UNITED STATES - $\hat{\jmath}$, holotype of Salvadora hexalepis deserticola; Texas, Brewster County, Government Spring, close to the Chisos Mountains; 6 Oct. 1935; Tom Carney leg.; FMNH 26615.

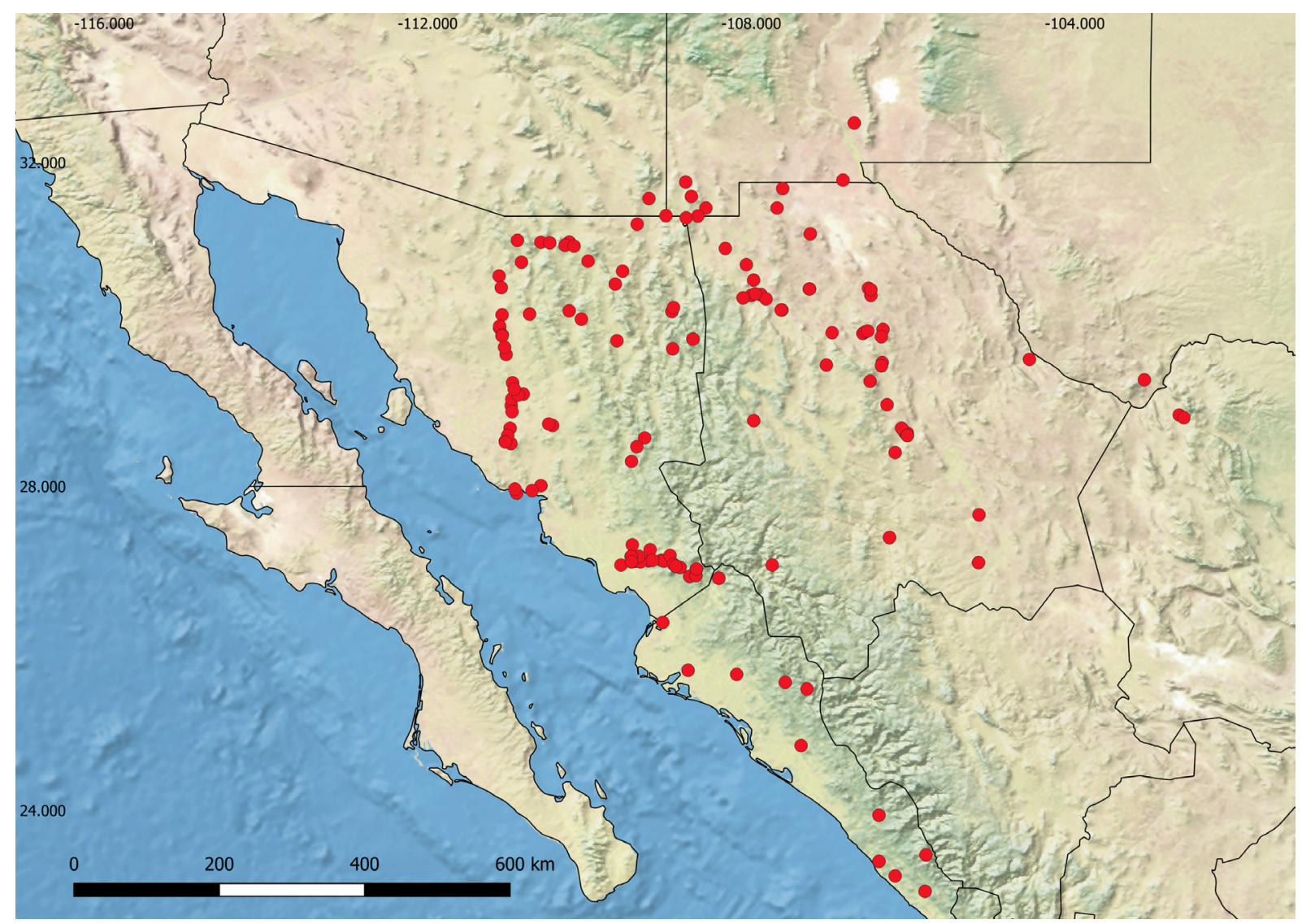

Fig. 6. Locality records of Salvadora deserticola Schmidt, 1940. 
MEXICO • + , holotype of Salvadora hexalepis celeris; Sinaloa, San Blas; 28 Mar. 1910; J.N. Rose leg.; USNM 40043.

\section{Distribution and conservation}

Southwestern Texas, southwestern New Mexico, and southeastern Arizona, southward on each flank of the Sierra Madre Occidental in Mexico in the states of Sonora, Chihuahua, Coahuila and Sinaloa (Fig. 6).

It is found in at least two protected natural areas in Sonora. Mexican legislation has not listed this species and the IUCN has it listed as a species of Least Concern.

Salvadora grahamiae Baird \& Girard, 1853

Fig. 7

Salvadora grahamiae Baird \& Girard, 1853: 104-105.

Phimothyra grahamiae - Cope 1861: 566.

\section{Diagnosis}

Well-developed rostral scale, elongated and with free edges; 8 or 9 supralabials, fourth and fifth or fifth and sixth supralabial in contact with the eye; normally 10 infralabials; a single loreal scale; preocular divided; prenasal scale in contact with the second supralabial; a second pair of chinshields separated by a row of scales; $178-200$ ventral scales and 89-106 subcaudals; maxillary teeth normally $10+3$. Color pattern consists of a pale vertebral line extending to the top of the head, three to five rows of scales wide on the first third of the body reduced to only three on posteriorly; head bordered by a pair of continuous dorsolateral lines from the loreal region throughout the body, with dark line on the sixth and seventh lines of dorsal scales; Sometimes with an inconspicuous lateral line at third row of dorsal scales.

Salvadora grahamiae differs from S. lineata by having inconspicuous or absent lateral lines, and differs from other congeners by having the tail approximately one quarter of the total length (22-29\%); loreal scale not divided, posterior chinshields separated by a two row of scales; and the vertebral line up to five scales wide on anterior of body.

\section{Etymology}

Dedicated to the collector of the taxon, J.D. Graham.

\section{Type material examined}

UNITED STATES - §’; Arizona, Cochise County, Huachuca Mountains, limited to Sonora (Bogert 1939a); J.D. Graham leg.; USNM 2081.

\section{Distribution and conservation}

From western Texas, northern Coahuila, Chihuahua, and Sonora to northern Arizona and New Mexico (Fig. 7). It occurs in several protected natural areas in Mexico and the United States. Mexico and the United States have not listed this species in any protection category, and it is on the IUCN red list as a species of Least Concern. 


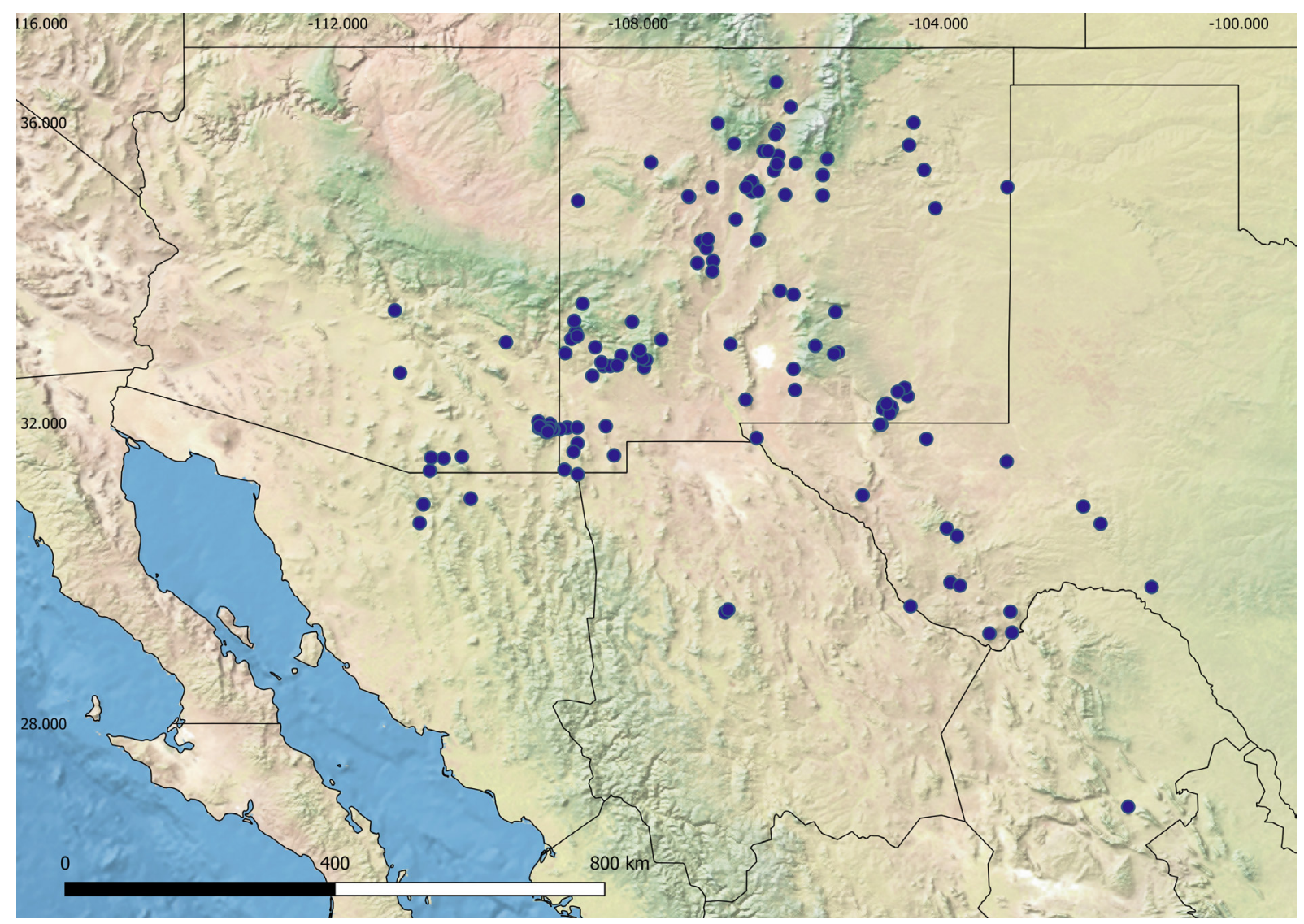

Fig. 7. Locality records of Salvadora grahamiae Baird \& Girard, 1853.

Salvadora lineata Schmidt, 1940

Fig. 8

Salvadora lineata Schmidt, 1940: 143-150.

Salvadora grahamiae lineata Hartweg, 1940: 259.

\section{Diagnosis}

Well-developed rostral scale, elongated and with free edges; 8 or 9 supralabials, fourth and fifth in contact with the eye; 9 to 11 infralabials; preocular divided; a single loreal scale; prenasal scale in contact with or separated from the second supralabial; a second pair of chinshields in contact with each other or separated by a row of scales; 179-202 ventral scales; 81-107 subcaudal scales; maxillary teeth normally $10+3$. Color pattern consists of a pale vertebral line reaching the top of the head, three to five rows of scales wide on the first third of the body and only three posteriorly; head bordered by a pair of continuous dorsolateral lines from the loreal region across the body, dark line on the sixth and seventh dorsal scales; lateral line paler than the well-developed dorsolateral line on the third row of dorsal scales.

Differs from S. grahamiae by having a pair of well-defined lateral lines on the third row of the dorsal scales, extending from the first third of the body and to the cloaca.

\section{Etymology}

Derived from the Latin 'linea', meaning 'line', in reference to the conspicuous lateral line. 


\section{Type material examined}

UNITED STATES • P; Texas, Kleberg County, Kingsville; 1938; J.C. Cross; FMNH 28605.

\section{Distribution and conservation}

United States from eastern Texas southward through northwestern Mexico in the states of Chihuahua, Coahuila, Nuevo León, Tamaulipas, Durango, Zacatecas, San Luis Potosí, Guanajuato Querétaro, Michoacán, Hidalgo, Puebla and northern Veracruz (Fig. 8).

This species occurs in several protected natural areas in Mexico and the United States. Mexico and the United States have not listed this species in any protection category, but it is on the IUCN red list as a species of Least Concern.

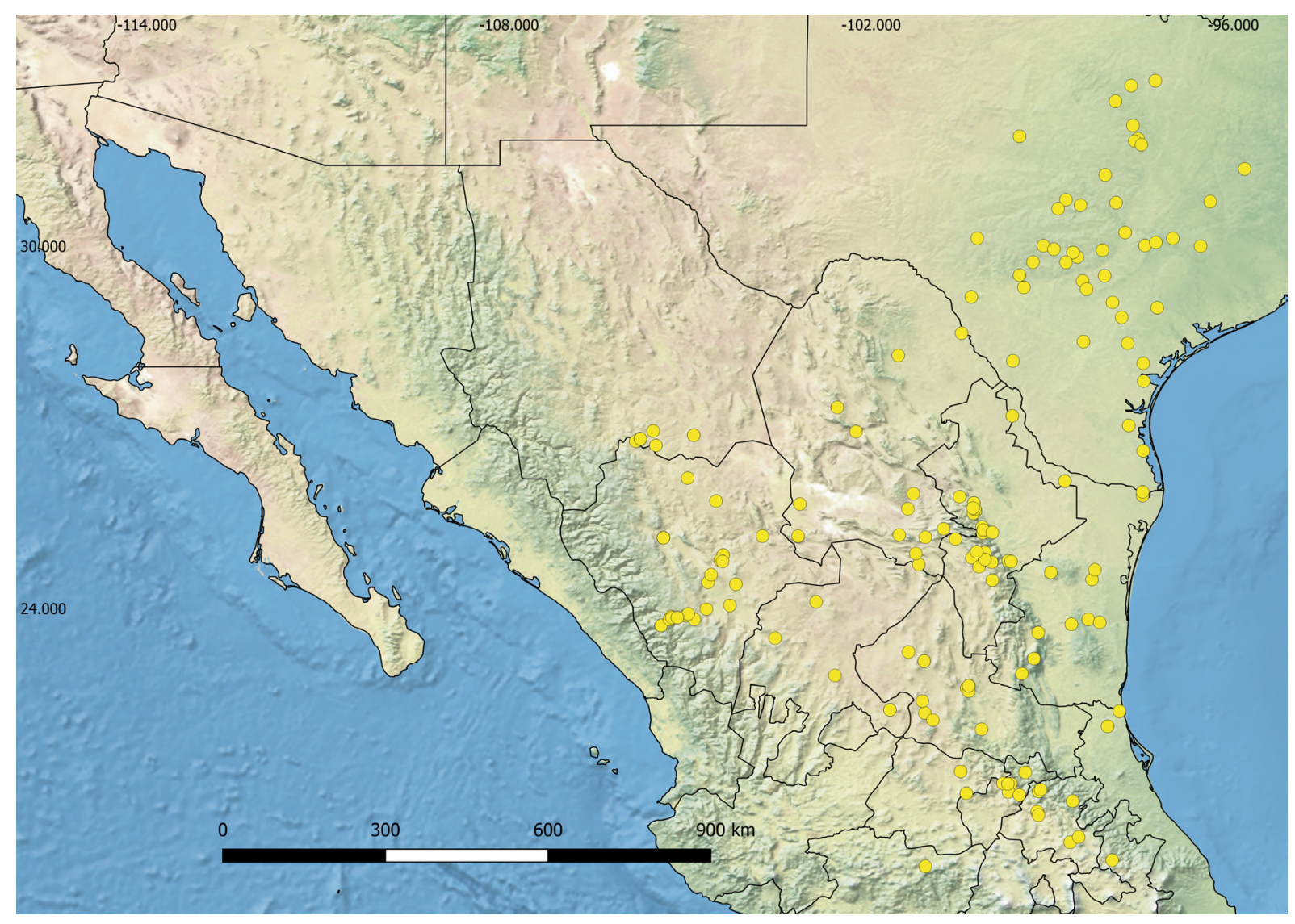

Fig. 8. Locality records of Salvadora lineata Schmidt, 1940.

Salvadora hexalepis (Cope, 1866)

Fig. 9

Phimothyra hexalepis Cope, 1866: 304.

\section{Subspecies included}

S. hexalepis hexalepis

S. hexalepis virgultea 


\section{S. hexalepis mojavesis}

S. hexalepis klauberi

\section{Diagnosis}

Well-developed rostral scale with free lateral edges; normally 9 supralabials, or occasionally 8 or 10 ; supralabials in contact with the eye, usually only sixth is in contact; 10-11 infralabials; preocular divided; loreal scale normally divided; prenasal scale separated from the second supralabial; a second pair of chinshields separated by two rows of scales; ventral scales 180-213; subcaudal scales vary from 75 to 103 ; maxillary teeth $10-12+3$. With the exception of $S$. hexalepis virgultea, the dark dorsolateral lines are normally separated from the lateral lines at the level of the third and fourth rows of dorsal scales; tail length is 20 to $26 \%$ of the total body length.

Salvadora hexalepis differs at the species level from the other species in the grahamiae group by having a divided preocular, fewer than 113 subcaudals, and a tail length less than $29 \%$ of the total length. It differs from S. grahamiae, S. intermedia, S. gymnorhachis and S. bairdi by having 9 to 10 supralabials, the sixth in contact with the eye versus 8 supralabials present in the other species in the grahamiae group. It differs from $S$. deserticola by having a divided loreal and 75-103 subcaudals.

\section{Type material examined}

UNITED STATES • Arizona, Fort Whipple; USNM 7894.

\section{Distribution and conservation}

This species occurs in the southwestern United States from Nevada, southern Utah, southward through California, Arizona, the Baja California Peninsula and Sonora including Tiburón, San José, and Espíritu Santo Islands in the Gulf of California. (Fig. 9).

Within its distribution, S. hexalepis has been recorded in several protected natural areas in Mexico and the United States. Mexico and the United States do not extend legal protection to this species. It is listed by the IUCN as a species of Least Concern.

\section{Salvadora hexalepis hexalepis (Cope, 1866)}

Fig. 9

\section{Diagnosis}

Nine supralabials; sixth supralabial in contact with the eye; 10 infralabials; a single subocular sometimes present; 186-213 ventrals; 75-98 subcaudals; tail 20 to $25 \%$ of total length; $10+3$ maxillary teeth; a pale vertebral line contacting the parietal region, three to five scale rows wide on the first third of the body, three rows wide posteriorly, bordered by a pair of dorsolateral lines up to four scale rows wide, extending from the temporal region to the tip of the tail, halfway along the body the dorsolateral lines are divided giving rise to another lateral line distinguishable to the tip of tail.

This taxon differs from $S$. h. klauberi by having a single supralabial in contact with the eye, whereas $S$. h. klauberi has two supralabials (the fifth and sixth) in contact; in $S . h$. mojavensis the supralabials and the lower edge of the eyes are separated by two or more suboculars; $S$. $h$. hexalepis is similar to $S$. $h$. virgultea in that many individuals have a single supralabial in contact with the eye; however, these subspecies differ in coloration pattern, with the head of $S$. $h$. virgultea being brown and the lateral line becoming faded and indistinguishable at about the middle of the body (in $S$. $h$. hexalepis the head is gray, the vertebral line is up to five rows of scales wide, and in the middle of the body the lateral line is completely separated from the dorsolateral line). 


\section{Etymology}

From the Latin 'hexa' for 'six' and 'lepis' for 'scale', which can be interpreted as six-sided scales.

\section{Distribution}

It occurs from the southeast of California, United States, southward to northeastern Baja California, central Arizona southward through the northeast portion of the Sonoran Desert, including Tiburón Island (Fig. 9).

\section{Salvadora hexalepis virgultea (Bogert, 1935)}

Fig. 9

Salvadora grahamiae virgultea Bogert, 1935: 89.

\section{Diagnosis}

Nine supralabials, the sixth or the fifth and sixth in contact with the eye; $10-11$ infralabials; suboculars absent; $188-200$ ventral scales; $84-103$ subcaudal scales; tail 21 to $26 \%$ of the total length; maxillary teeth $10+3$. A pale vertebral line three rows of scales wide is in contact with the parietal region, bordered by a pair of dorsolateral lines brown in color, five rows of scales wide extending from the temporal region to the tip of the tail. At about midbody the lateral line gives rise to a thinner lateral line that is one row of scales wide.

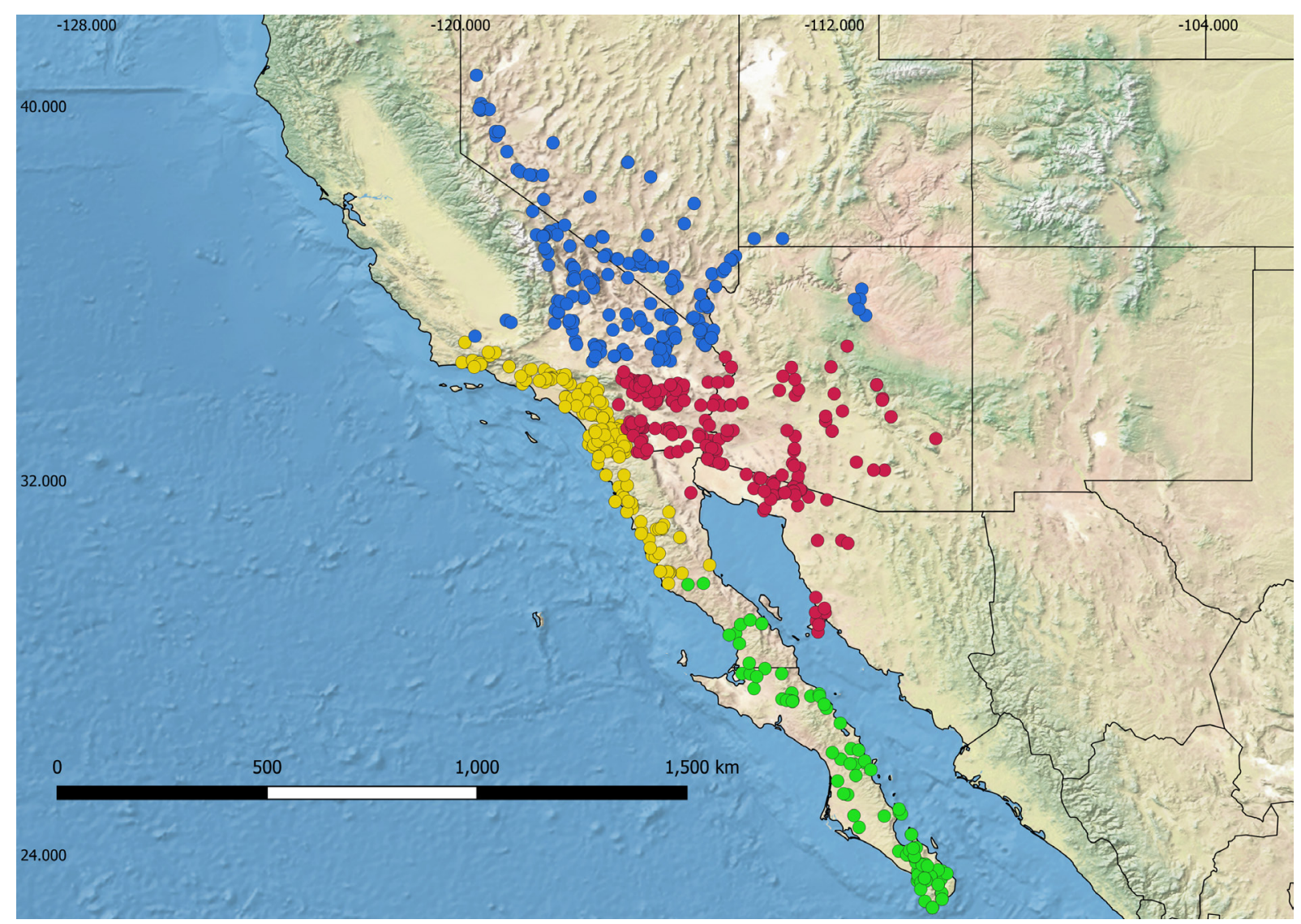

Fig. 9. Locality records of Salvadora hexalepis (Cope, 1866) and its subspecies. Blue dots represent S. h. mojavensis Bogert, 1945; yellow dots $S$. h. virgultea Bogert, 1935; red dots S. h. hexalepis (Cope, 1866) and green dots S. h. klauberi Bogert, 1945. 
Salvadora $h$. klauberi differs in having $12+3$ maxillary teeth; in $S . h$. mojavensis suboculars separate the supralabials from the lower edge of the eye; $S$. h. hexalepis sometimes also lacks suboculars and has a single supralabial in contact with the eye similar to $S$. $h$. virgultea, but it differs in its color pattern (in $S$. $h$. virgultea the vertebral line involves three scale rows; the head is brown, and a lateral line is not distinguishable). In $S$. $h$. hexalepis the vertebral line is up to five scale rows wide; the head is gray; and the lateral line at midbody is completely separated from the dorsolateral line.

\section{Etymology}

From the Latin 'virgultus', meaning 'covered with scrub', for the habitat in which the taxon occurs.

\section{Type material examined}

UNITED STATES - O'; California, San Diego County; $32.67778^{\circ}$ N, $116.72709^{\circ}$ W; 29 Jun. 1929; Deerhorn Flat leg.; SDSNH 12025.

\section{Distribution}

Regions adjacent to the Pacific coast and adjacent foothills in southwestern California, southward to the southern portion of Baja California, where is it parapatric with S. h. kaluberi (Fig. 9).

\section{Salvadora hexalepis mojavensis Bogert, 1935}

Fig. 9

Salvadora hexalepis mojavensis Bogert, 1945: 14.

\section{Diagnosis}

Nine supralabials, no supralabial in contact with the eye or only sixth in contact; 10-11 infralabials; from two to three suboculars; $190-207$ ventral scales; $82-96$ subcaudal scales; tail 20 to $25 \%$ of total length; $11+3$ maxillary teeth; a pale vertebral line that does not reach the parietal region, bordered by a pair of dorsolateral lines and a pair of somewhat inconspicuous lateral lines and irregular bars along the body that interrupt the dorsolateral and lateral lines.

Differs from all conspecific subspecies by having two or three suboculars present.

\section{Etymology}

Toponym alluding to its distribution that is concentrated in the Mojave Desert.

\section{Type material examined}

UNITED STATES • ${ }^{\lambda}$; California, San Bernardino County, Deadman Point, 11.5 miles SE of Victorville, at the south end of the Granite Mountains; 19 Jun. 1935; C.M. Bogert leg; AMNH 63000.

\section{Distribution}

Endemic to the United States. Distributed south of the San Joaquín Valley and the Mojave Desert, east and north of the foothills of the San Gabriel and San Bernardino mountains, to Pyramid Lake in western Nevada, the Virgin River Basin in southern to western Utah, and portions of the Painted Desert in northern Arizona near the Grand Canyon and the canyon of the small Colorado River (Fig. 9).

Salvadora hexalepis klauberi Bogert, 1945

Fig. 9

Salvadora hexalepis klauberi Bogert, 1945: 14. 


\section{Diagnosis}

Nine supralabials, generally fifth and sixth in contact with the eye; $10-11$ infralabials; suboculars normally absent; 180-203 ventral scales; $78-99$ subcaudal scales; tail 21 to $26 \%$ of total length; $12+3$ maxillary teeth; a pale vertebral line three to five rows wide contacting the parietal region, bordered by a pair of dark dorsolateral lines up to four rows wide extending from the temporal region to the margins between the fifth and fourth rows of scales, lateral lines one or two scales wide fused with the dorsolateral lines on first third of the body.

Differs from $S$. h. mojavensis by lacking suboculars, differs from $S$. h. hexalepis by having fifth and sixth supralabials bordering the eye and differs from $S$. $h$. virgultea by having $12+3$ maxillary teeth.

\section{Etymology}

Dedicated to Laurence Monroe Klauber.

\section{Type material}

MEXICO • đ̊; Baja California Sur, Cape San Lucas; 6 Aug. 1933; Fred Lewis leg.; Collection of L.M. Klauber No. 20912.

\section{Distribution}

Endemic to Mexico, present from northern Baja California southward through Baja California Sur, including the San José and Espíritu Santo Islands (Fig. 9).

\section{Salvadora intermedia Hartweg, 1940}

Fig. 10

Salvadora intermedia Hartweg, 1940: 256-259.

Salvadora intermedia richardi Smith, 1941: 6-9.

Salvadora intermedia intermedia - Smith, 1941: 7.

\section{Diagnosis}

Rostral scale elongated; generally 8 supralabials (occasionally 9), the fourth and fifth normally in contact with the eye; 10-11 infralabials; preocular scale divided; a single loreal scale; prenasal scale in contact with or separated from the second supralabial; chinshields in contact or separated by two small scales; ventral scales 172 to 190 ; subcaudal scales 84 to 114 ; tail is 23 to $30 \%$ of the total length; $11+3$ maxillary teeth. Color pattern formed by a vertebral line three scales rows wide, yellowish in color and in contact with the parietal region; a pair of lateral lines is fused with the dorsolateral lines on first third of body, separated at second third of the body to tail; dorsolateral lines wide and dark, diverging at the neck, passing through the temporal region to eye.

Salvadora intermedia differs from its congeners by having a divided preocular scale; fewer than 116 subcaudal scales; 8 supralabials, the fourth and fifth in contact with the eye; the second pair of chinshields in contact with each other or separated by a row of scales; and two dark dorsolateral lines that diverge at the neck, passing through the temporal to eye.

\section{Type material examined}

MEXICO • $\widehat{\jmath}$, holotype of Salvadora intermedia intermedia; Guerrero, vicinity of Chilpancingo; W.W. Brown leg.; UMMZ 85733. 
MEXICO • $\widehat{T}$, holotype of Salvadora intermedia richardi; Puebla, 1 mile N of Tehuacán; 8 Aug. 1940; R.C. Taylor leg.; Collection E.H. Taylor and H.M. Smith No. 23470; UIMNH 25071.

\section{Distribution and conservation}

Endemic to Mexico. Distributed in central-southern Mexico from the vicinity of Chilpancingo, Guerrero, eastward through central Oaxaca and northward to southwestern Puebla (Fig. 10).

Within its distribution it is found in at least two protected natural areas. Mexican legislation has listed this species as subject to Special Protection and the IUCN has it listed as a species of Least Concern.

\section{Remarks}

Salvadore intermedia richardi was described by Smith (1941), who based his description on a single specimen collected one mile from Tehuacán, Puebla (UIMNH 25071). Smith (1941) thought this specimen represented a disjunct population of the populations of $S$. intermedia at Guerrero. Smith (1941) defined S. intermedia richardi as having the prenasal scale separated from the second supralabial and by its number of ventral scales. However, we examined 37 individuals of $S$. intermedia along what appears to be a continuous distribution from Guerrero and through Oaxaca to southern Puebla, and found that only seven of these specimens had the condition of the prenasal scale separated from the second supralabial described by Smith (1941): three from Oaxaca (MZFC 04059, MZFC 23857, MZFC 23871), three from Guerrero (MCZ 33642, MZFC 02878, FMNH 109866), one from Puebla (MZFC 14384). Additionally, the number of ventral scales of these specimens falls within the range previously described for $S$. intermedia. Based on these findings, we conclude that these characters are part of the

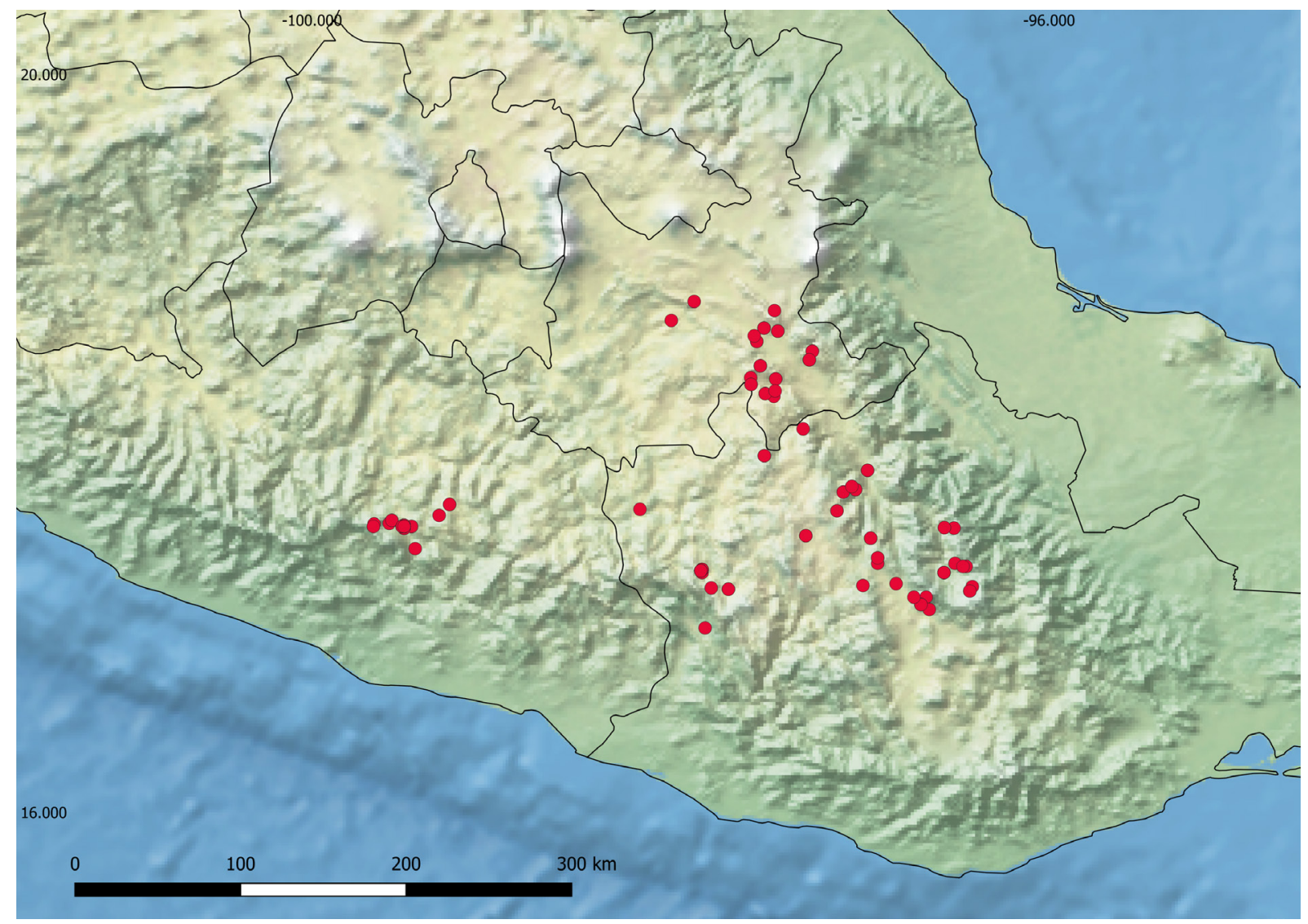

Fig. 10. Locality records of Salvadora intermedia Hartweg, 1940. 
intrapopulational variation of $S$. intermedia and that $S$. i. richardi should be considered a junior synonym of $S$. intermedia as previously suggested by Davis \& Dixon (1957).

Salvadora gymnorhachis Hernández, Flores \& Campbell, 2019

Fig. 11

\section{Diagnosis}

Eight-9 supralabials, two supralabials, fourth and fifth in contact with the eye; 8-10 infralabials; preocular scale divided; a single loreal scale; prenasal in contact or separated from the second supralabial; a second pair of chinshields in contact or separated by a row of scales; $176-186$ ventral scales; $92-103$ subcaudal scales; tail is 18 to $21 \%$ of the total length; $11+3$ maxillary teeth. Color pattern consists of a pair of dark dorsolateral lines that begin behind the eyes and fade before reaching the middle of the body, without a well-defined vertebral line and lacking lateral lines.

This species differs clearly from the other species by lacking dorsolateral lines on about the posterior two-thirds of the body and by lacking vertebral and lateral lines across the body.

\section{Etymology}

The name is derived from the Greek prefixes 'gymnós', which means 'naked' and 'ráchi' which means 'back'.

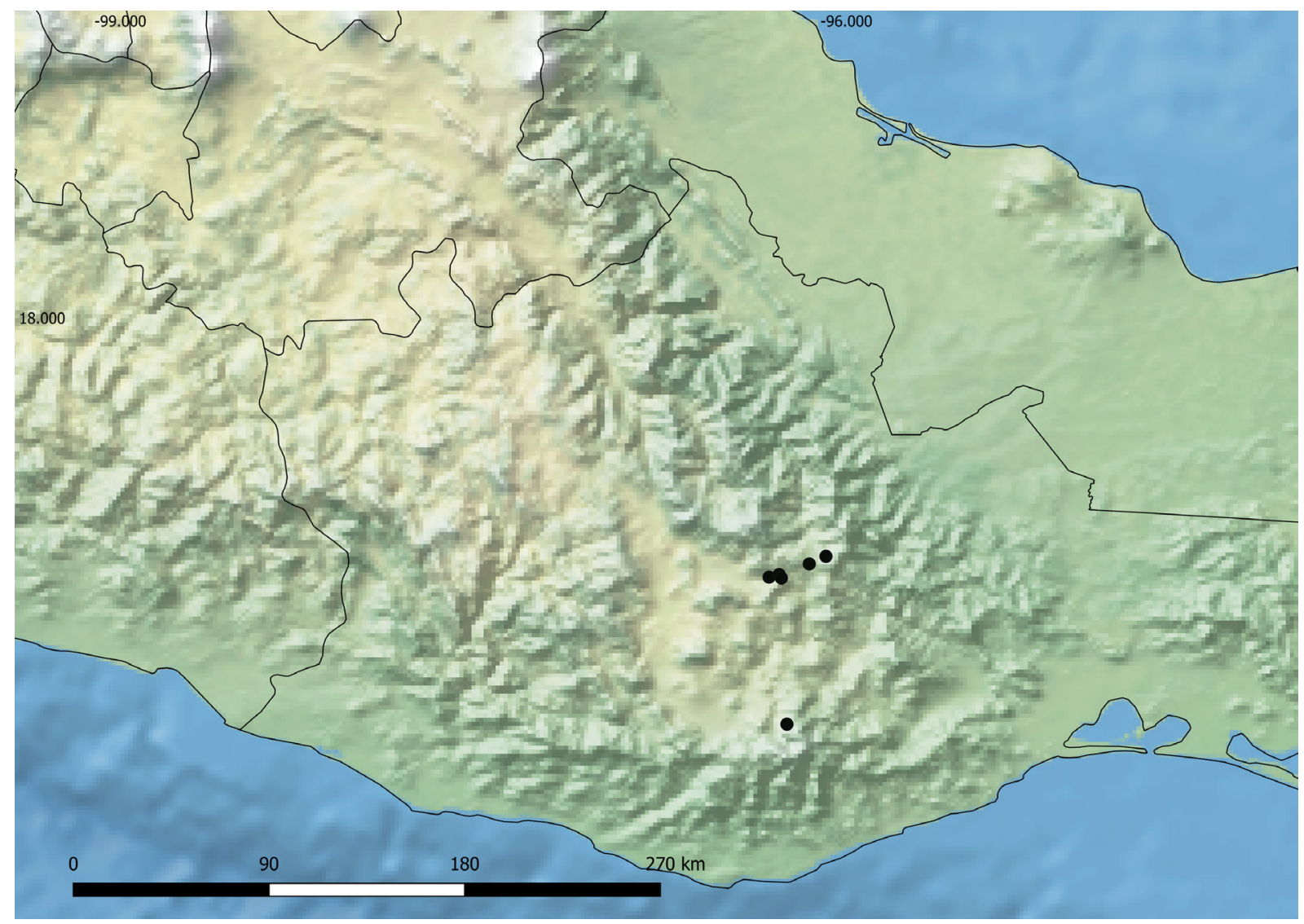

Fig. 11. Locality records of Salvadora gymnorhachis Hernández-Jiménez, Flores-Villela \& Campbell, 2019. 


\section{Type material examined}

MEXICO • 9 ; Oaxaca, Distrito Mixe, San Pedro and San Pedro Ayutla; $17.00159^{\circ}$ N, $96.08443^{\circ}$ W; 24 Aug. 2014; MZFC 28775.

\section{Distribution and conservation}

Mountains of central Oaxaca, Mexico (Fig.11).

This is a recently described taxon and one of limited distribution that is not known to inhabit any protected natural areas. This species is not included in Mexican legislation and is not in the IUCN's red list.

\section{Dichotomous key for the species and subspecies of the genus Salvadora}

1. A single preocular (Fig. 12A); more than 123 subcaudals; three supralabials in contact with the eye; maxillary teeth $14+3$ to $15+3$; tail length more than $29 \%$ of total body length (mexicana group). 2

- Preocular generally divided (Fig. 12B); fewer than 116 subcaudals; normally fewer than three supralabials in contact with the eye; maxillary teeth from $9+3$ to $12+3$; tail length generally less than $29 \%$ of total body length (grahamiae group).
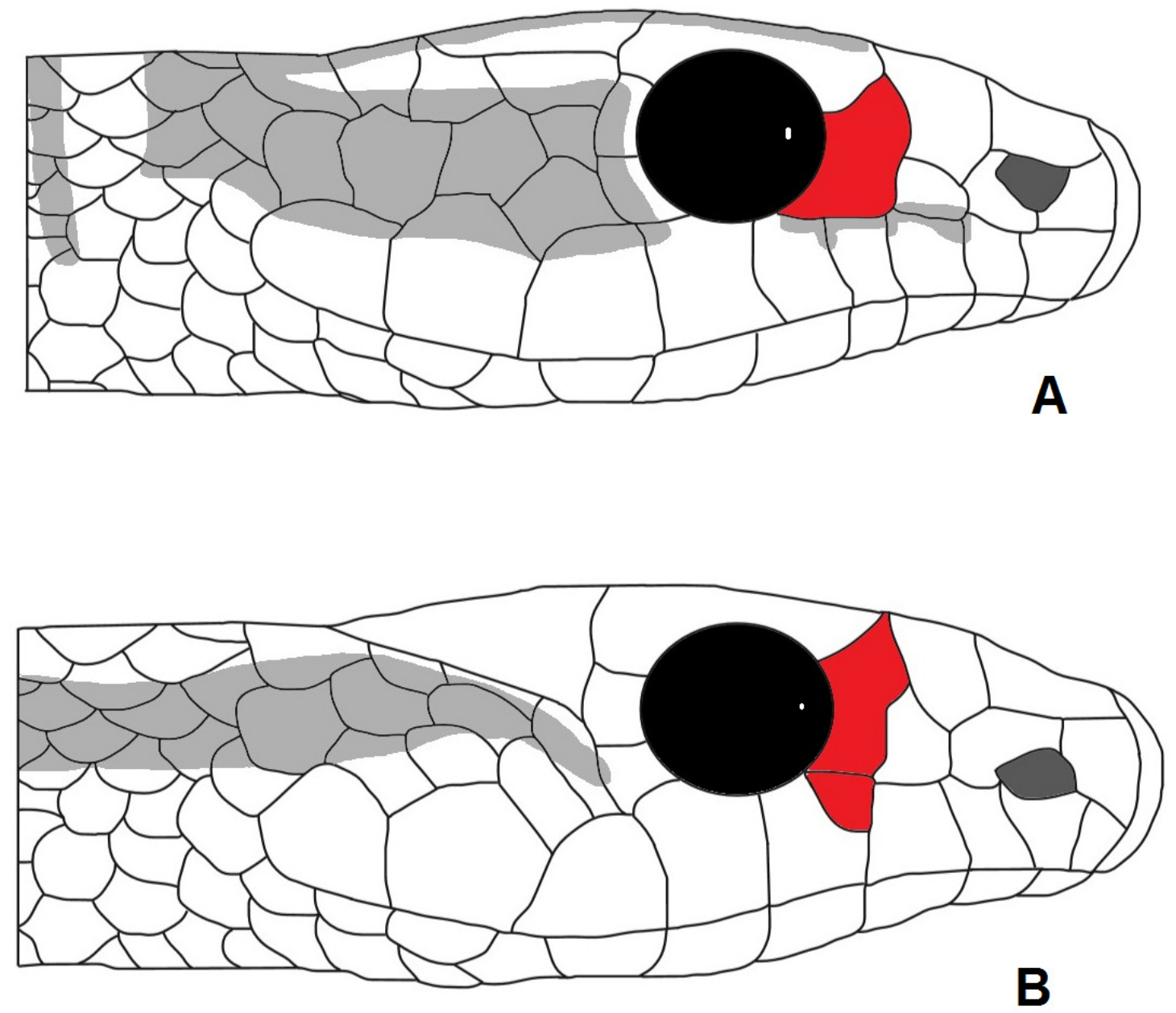

Fig. 12. A. Single preocular. B. Preocular generally divided. 
2. Four longitudinal lines on the posterior part of the body that are interrupted in the first third of the body by transverse patches or crossbars (Fig. 13A); $182-197$ ventral scales; tail length $31 \%$ to $42 \%$ of total length; maxillary teeth $15+3$

S. mexicana (Duméril, Bibron \& Duméril, 1854)

- Four well-defined longitudinal lines extending along the body without transverse patches or crossbars on the first third of body (Fig. 13B); 194 to 205 ventral scales; tail length between $29 \%$ and 33\% of total length; maxillary teeth $14+3$

S. lemniscate (Cope, 1895)

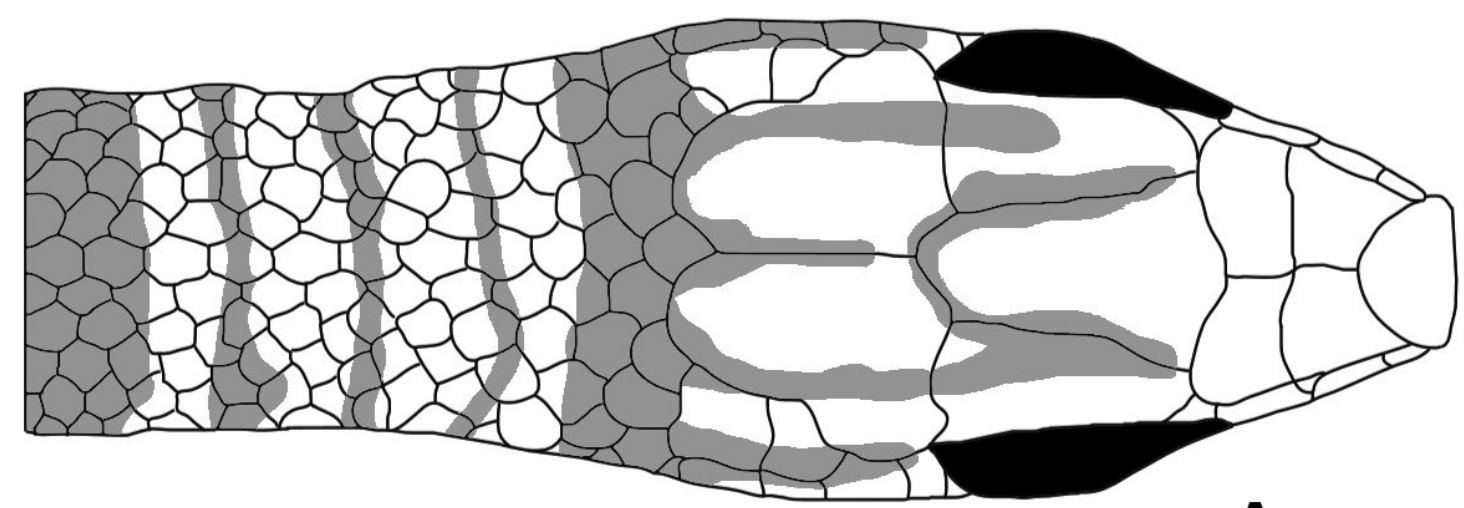

A

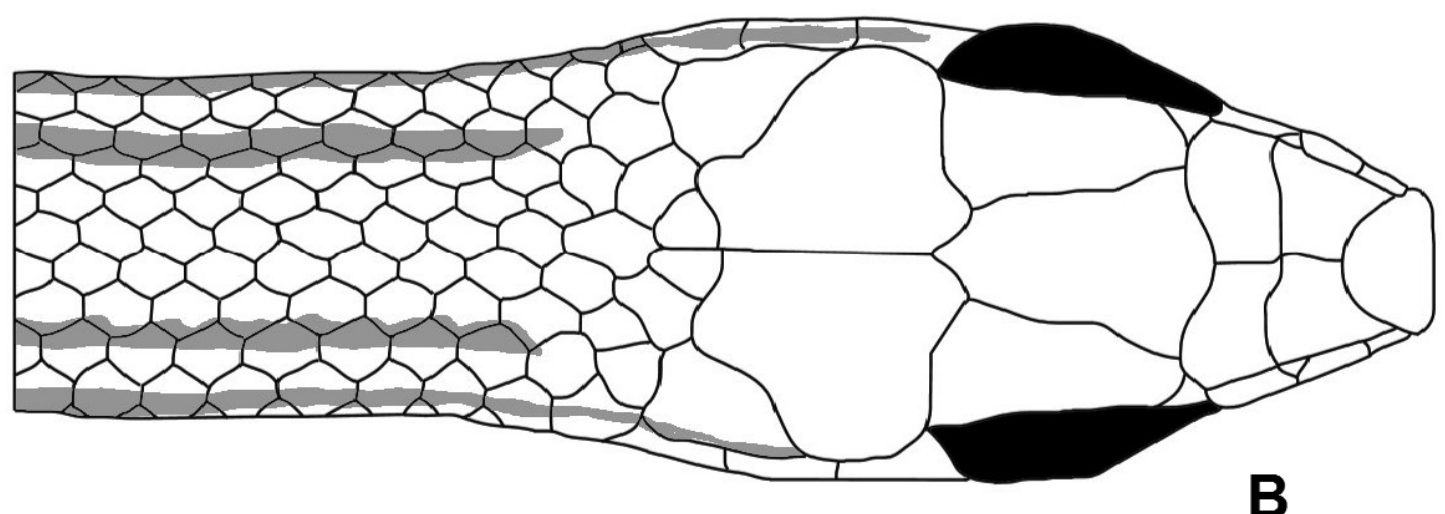

Fig. 13. A. Longitudinal lines interrupted in the first third of the body. B. Longitudinal lines extending along the body.

3. Supralabials normally eight (rarely 7 or 9), fourth and fifth in contact with the eye (Fig. 14A); a second pair of chinshields in contact with each other or separated by one row of scales (Fig. 15A

- Nine or ten supralabials (rarely 11 or 12), generally the sixth is in contact with the eye (Fig. 14B); posterior pair of chinshields sometimes separated by two rows of scales (Fig.15B)....

4. Maxillary teeth $11+3$; dorsolateral lines normally present along the body or incomplete present only in the first third of body, lateral line normally present on third or fourth row of dorsal scales, or absent when the dorsolateral line is incomplete (populations from Guerrero, Oaxaca or south of Puebla). 

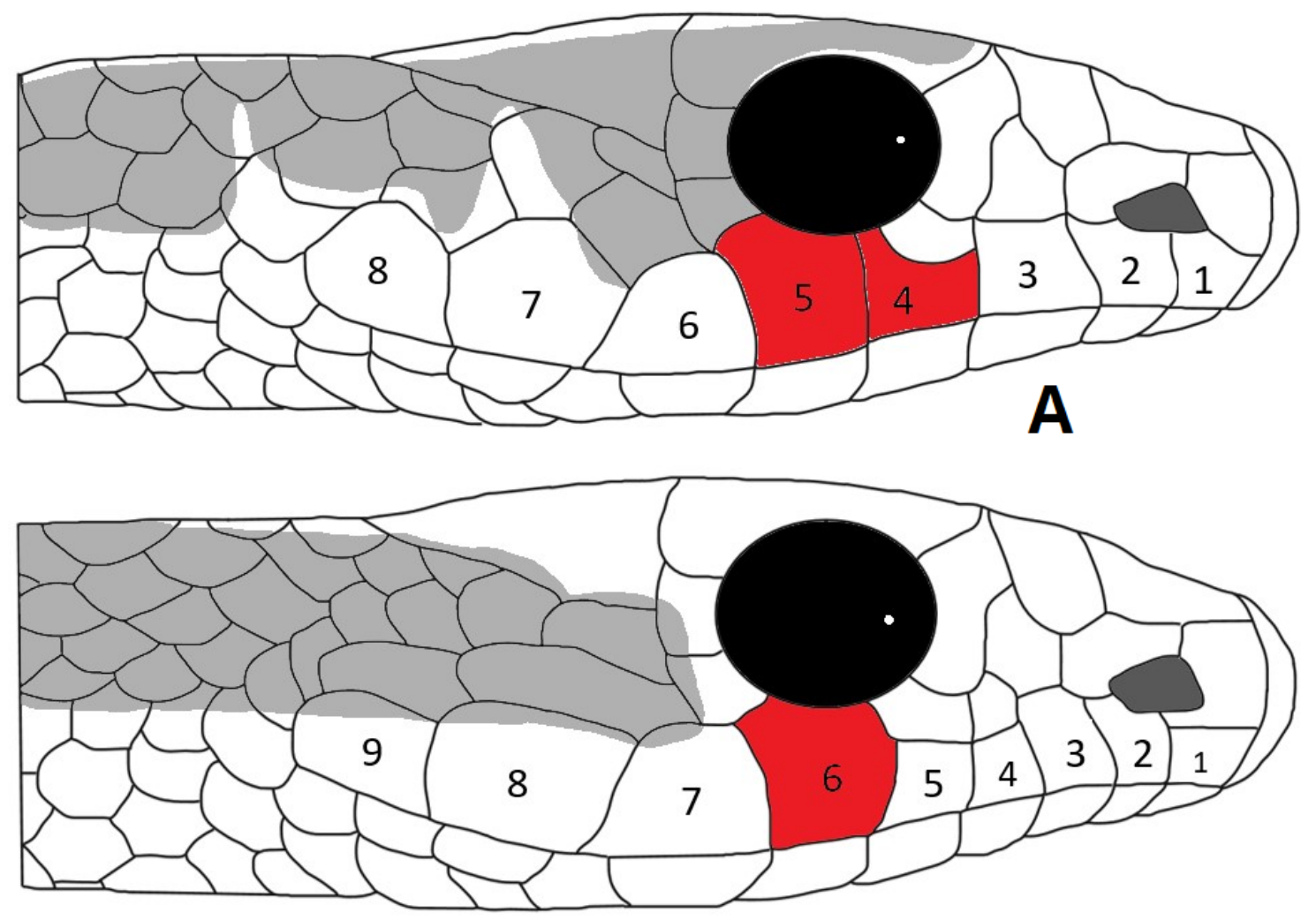

B

Fig. 14. A. Supralabials fourth and fifth in contact with the eye. B. Sixth supralabial in contact with the eye.

- Maxillary teeth $9+3$ or $10+3$; dorsolateral line always present; lateral line well defined on the third or fourth row of dorsal scales, or vestigial or absent. 6

5. Dorsolateral lines present along the entire body; a light, yellowish vertebral line; lateral lines always present; tail length 23 to $30 \%$ of total body length

S. intermedia Hartweg, 1940

- Dorsolateral lines absent on the second and last third of the body; no lateral lines on body; tail length is 19 to $21 \%$ of total length

S. gymnorhachis Hernández-Jiménez, Flores-Villela \& Campbell, 2019

6. Maxillary teeth $9+3$; vertebral line normally separated from the parietal region by a patch formed by the fusion of the dorsolateral lines (Fig. 16A); dorsolateral lines do not reach the temporal region; vertebral line three scale rows wide on the first and second third of the body (sometimes interrupted by dark blotches), and one row wide on the last third; lateral line well defined and separated from the dorsolateral line the entire length of the body

S. bairdi Jan \& Sordelli, 1860

- Maxillary teeth 10+3; vertebral line reaching the parietal region (Fig. 16B); dorsolateral lines pass through the temporal region to the eye; vertebral line from three to five rows wide on the first third of the body, and three rows wide on the second and last third of the body; lateral line present, vestigial or barely discernible, or may be absent in some specimens..... 

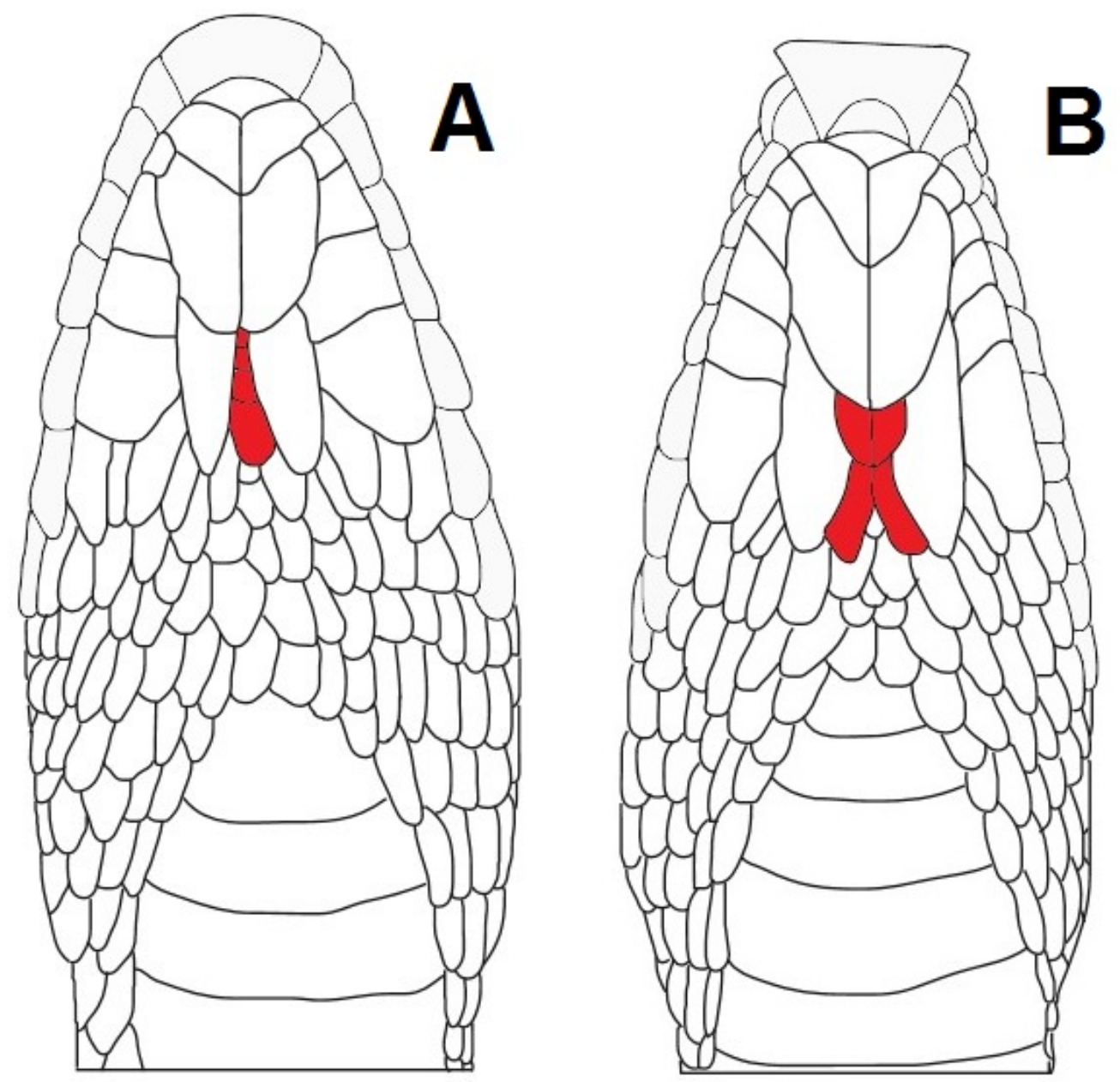

Fig. 15. A. Second pair of chinshields separated by one row of scales. B. Second pair of chinshields separated by two rows of scales.

7. Lateral line absent, vestigial, or scarcely discernible (Fig. 17A)

- Lateral line always present and well defined (Fig. 17B)

S. grahamiae Baird \& Girard, 1853 S. lineata Schmidt, 1940

8. Loreal scale normally single (Fig. 18A); vertebral line five rows wide on the first third of body; lateral line well defined, largely restricted to adjoining margins of scales in third and fourth rows, clearly separated from the dorsolateral line on the second and last thirds of body; 68 to 86 subcaudals

S. deserticola Schmidt, 1940

- Loreal normally divided (Fig. 18B); vertebral line generally 3 rows wide, sometimes more; lateral line ill-defined or well-defined but fused or feebly separated from the dorsolateral lines; 75 to 103 subcaudals.....

9. Vertebral line yellowish in color, no more than three scale rows in width along the entire body; dorsolateral lines brown fused with the lateral lines in the anterior part of body but feebly separated posteriorly, generally without subocular scales, overall appearance brown. 

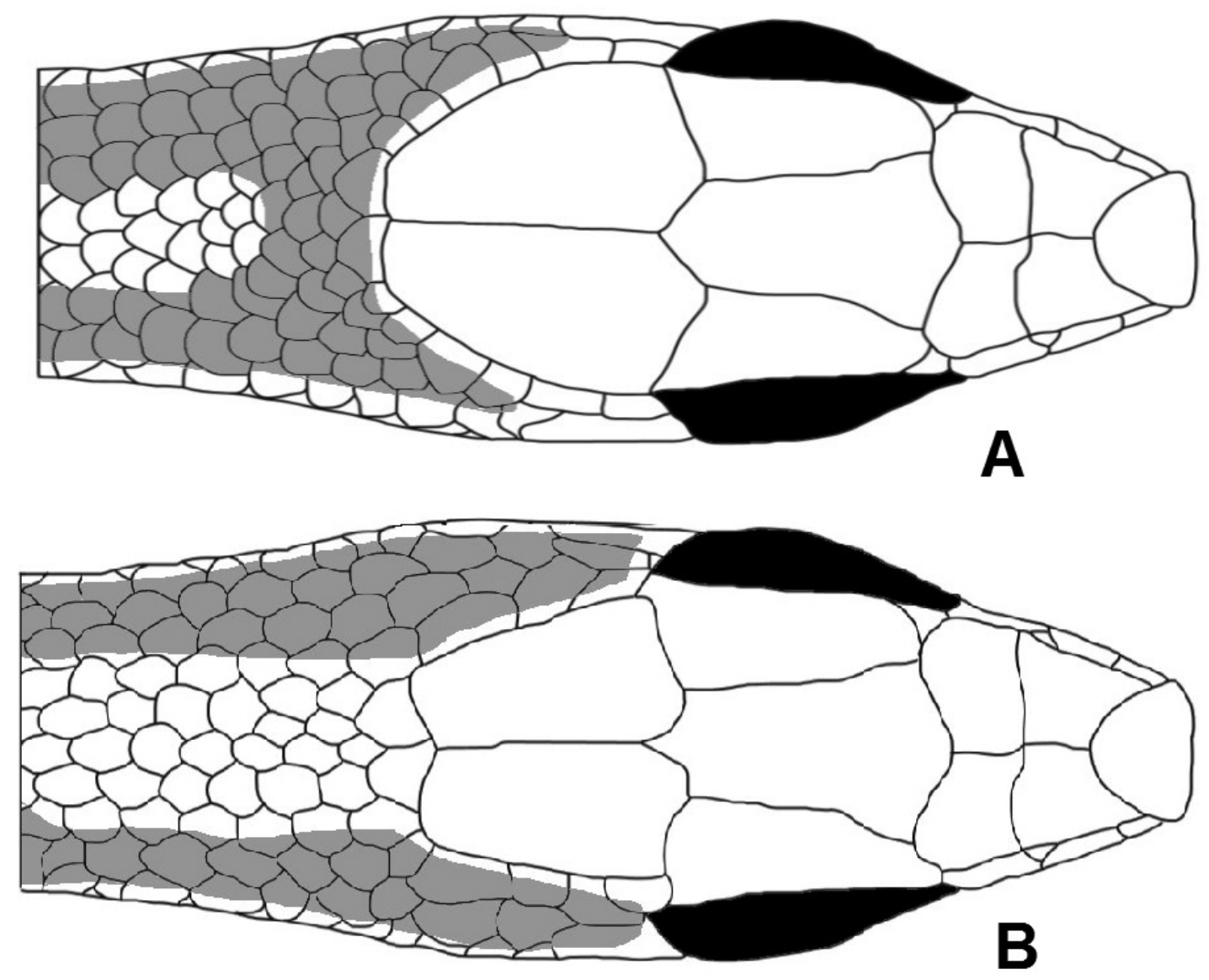

Fig. 16. A. Vertebral line normally separated from the parietal region. B. Vertebral line reaching the parietal region.

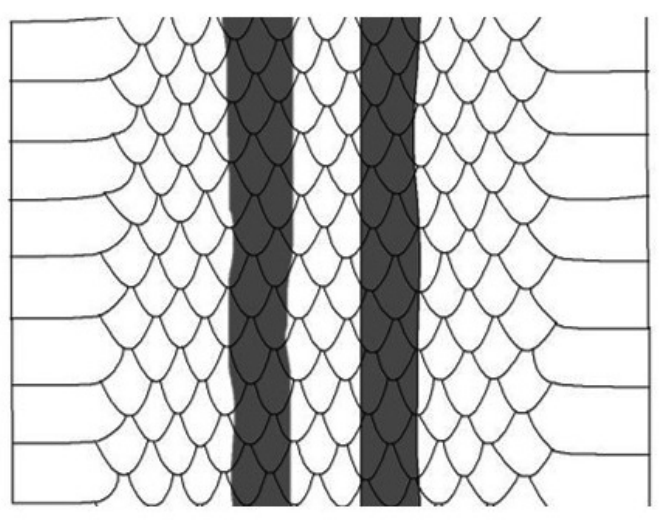

A

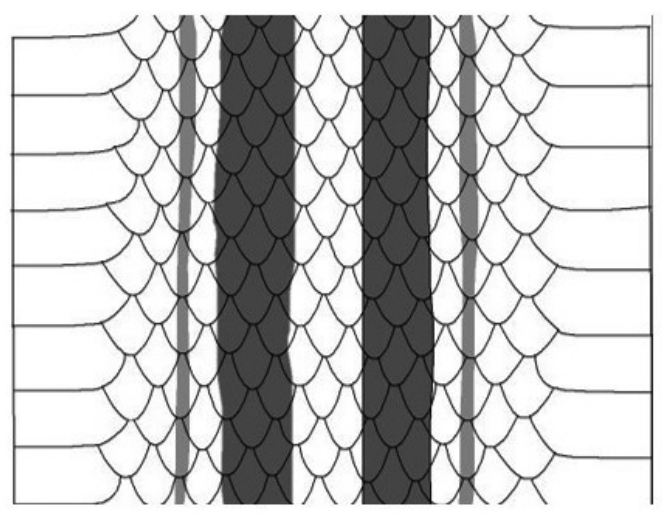

B

Fig. 17. A. Lateral line absent. B. Lateral line always present and well defined. 


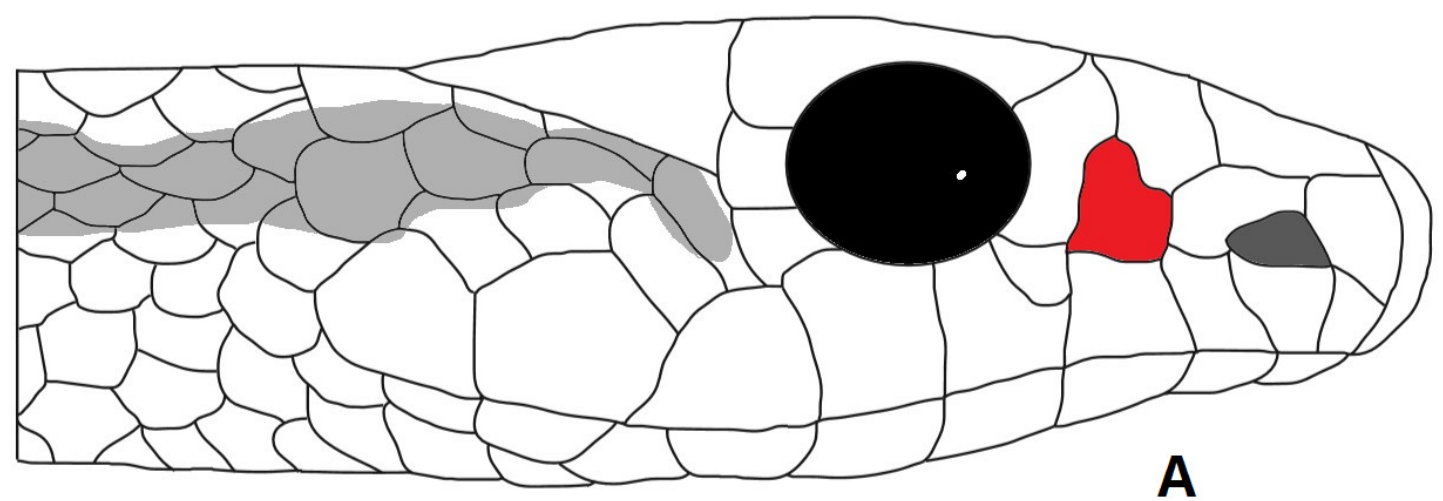

A

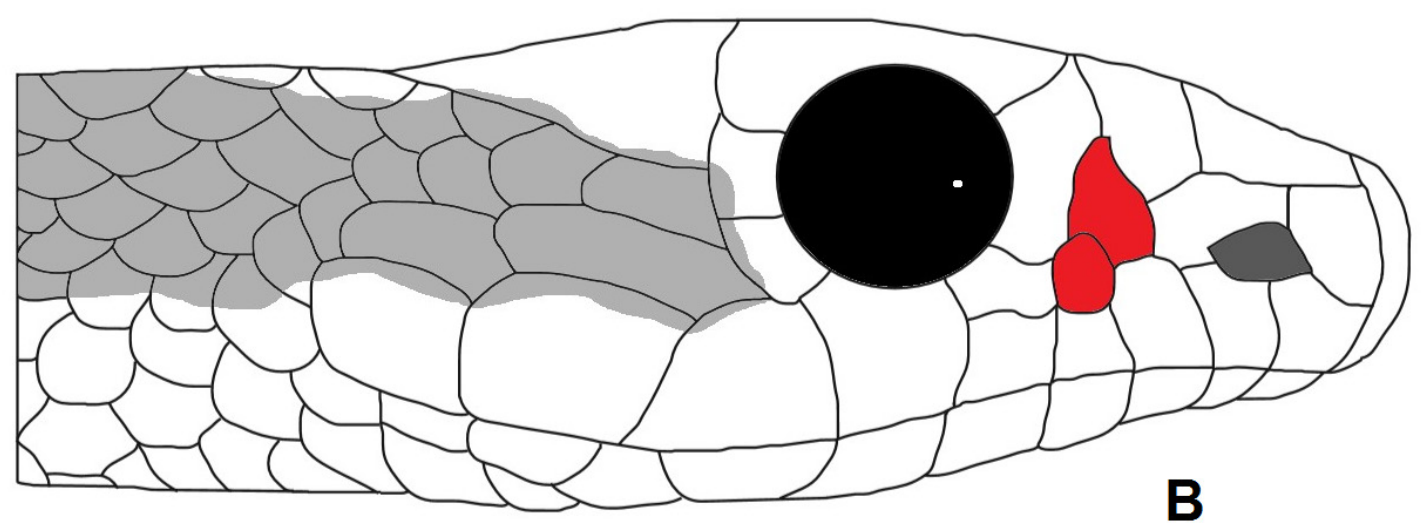

Fig. 18. A. Loreal scale single. B. Loreal normally divided.

- Vertebral line light grey in color, more than three rows wide (3 to 7) on the first third of the body; dorsolateral lines brown or grey in color, and four rows wide on the first third of the body, three rows wide in the second and one row wide on the last third of the body, and regularly separated or slightly separated from the lateral lines, with or without subocular scales ....

10. Normally two supralabials reaching the eye (Fig. 19A); $12+3$ maxillary teeth

- Fewer than two supralabial reaching the eye (Fig. 19B); 10 or $11+3$ maxillary teeth

S. h. klauberi Bogert, 1945

11. Supralabials normally separated from the eye by the presence of two or more subocular scales (Fig. 20A);10-11 infralabial scales; 11+3 maxillary teeth; sometimes with an irregular pattern of bars running the length of the body that interrupt the dorsolateral and lateral lines......

S. h. mojavensis Bogert, 1945

- One supralabial in contact with the eye (Fig. 20B); normally without suboculars or when present there is only one; normally 10 infralabials; $10+3$ maxillary teeth; vertebral line three scales in width; dorsolateral line nearly gray, often irregularly pigmented, and obscurely separated from lateral line anteriorly, over-all appearance gray..... 

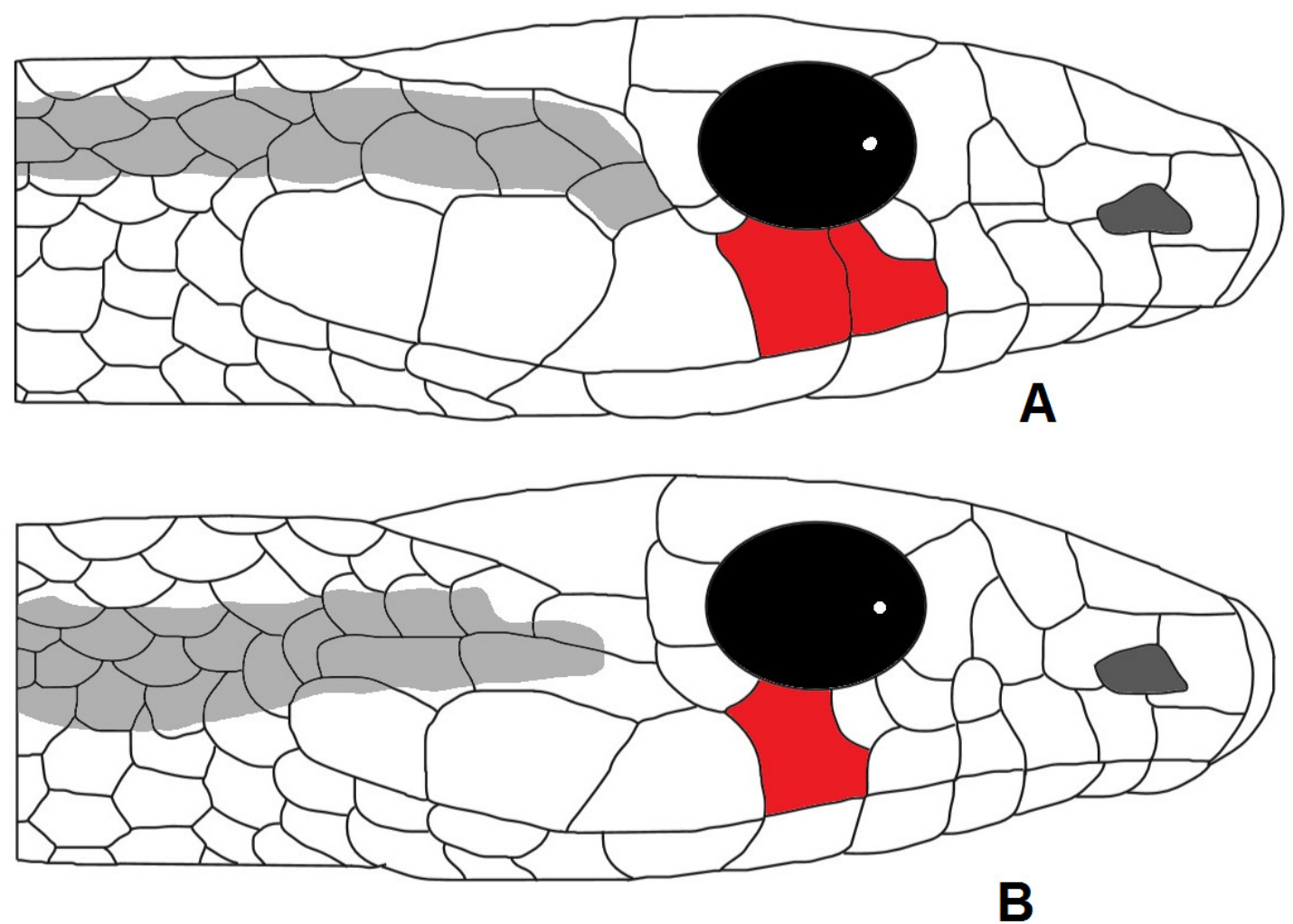

Fig. 19. A. Two supralabials reaching the eye. B. Fewer than two supralabials reaching the eye.
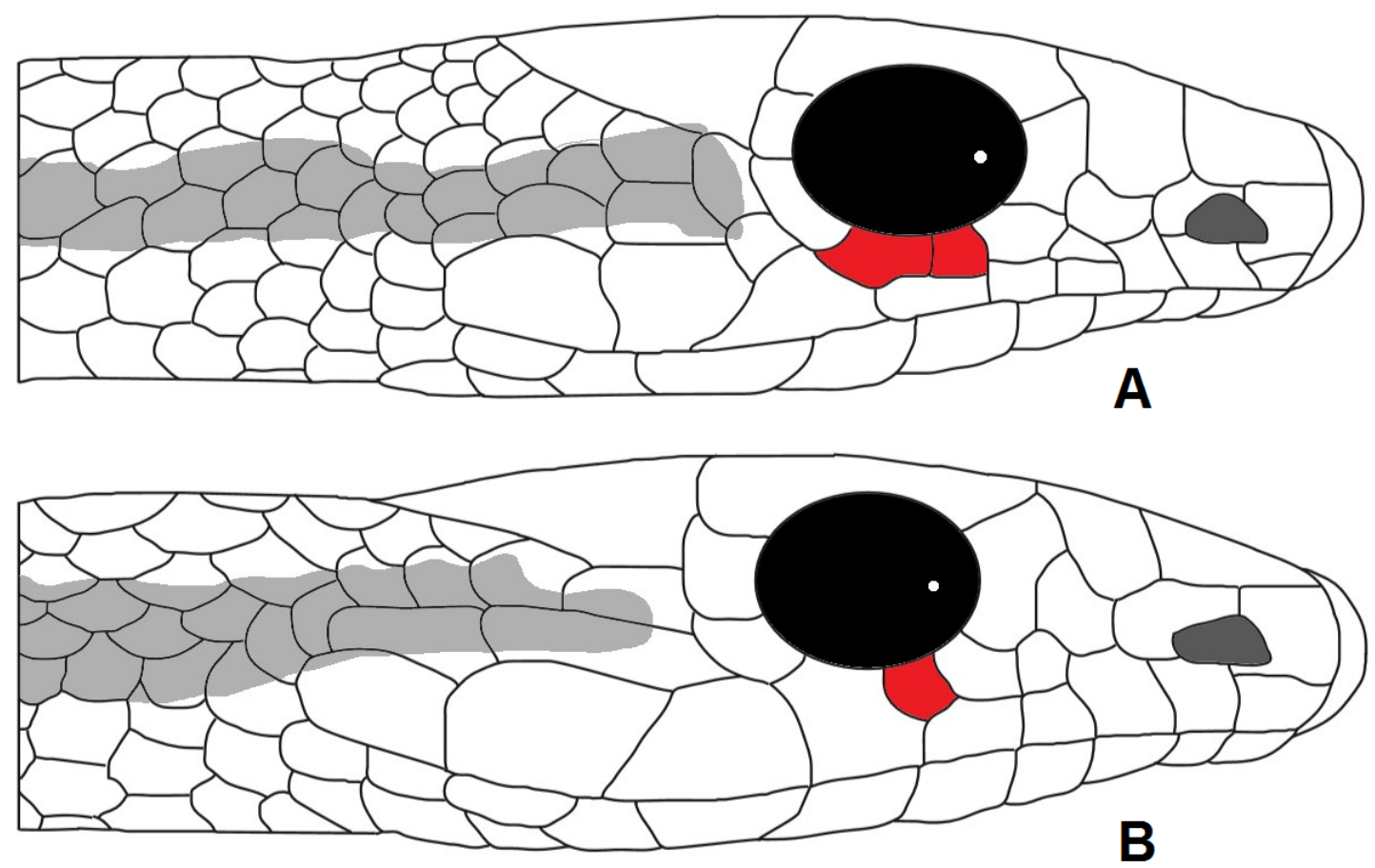

Fig. 20. A. Two or more subocular scales. B. One supralabial in contact with the eye. 


\section{Discussion}

The genus Salvadora is a monophyletic group supported by several morphological synopomorphies, including enlarged rostral (usually with free edges), partially intervening between internasals; dorsal scales 17-17-13; and dorsolateral lines on at least one-third of body. Lannutti (2000) in an unpublished thesis reported a monophyletic Salvadora, including the genus Leptodrymus. Lannutti (2000) used a different set of morphological characters and in his analyses used gap weighing as proposed by Thiele (1993). We also use the method of Thiele, but polymorphic characters were subjected to splitting into bins, as suggested by Wiens (1995). We used Fast Morphology (Smith \& Gutberlet 2001), which incorporates as much variation as possible in polymorphic characters and analyzed them in a way to allow a parsimony algorithm to improve the results giving a workable hypothesis of relationships. Our results agree with those of the molecular hypothesis proposed by Hernández-Jiménez et al. (2019), which recovered Salvadora as monophyletic. However, in the molecular based phylogenies of Figueroa et al. (2016) and Tonini et al. (2016), Salvadora does not appear as a monophyletic group, though their phylogenies did not include all the species of the group.

The phylogeny presented here found Leptodrymus to be a sister taxon to Salvadora, placed at the base of the monophyletic Salvadora. Our preliminary molecular data show Leptodrymus in a separate clade from that of Salvadora in agreement with the phylogenetic hypothesis of Tonini et al. (2016). Bogert (1947) proposed Salvadora and Leptodrymus as separate genera in his investigation of the relationships of Leptodrymus with other colubrid genera. Based on our analysis, we maintain L. pulcherrimus separate from Salvadora. Some of the characters that place Leptodrymus close to Salvadora may be convergent, such as the enlarged rostral and the pattern of longitudinal lines on the dorsum. Even with these characters, Leptodrymus does not fall in the ingroup with Salvadora, as occurred in the analysis of Lannutti (2000).

Our morphological cladogram supports the two groups that Smith $(1938,1941)$ suggested exist within the genus. These were also corroborated in the molecular phylogeny by Hernández-Jiménez et al. (2019) placed S. mexicana at the base of the phylogeny, being the sister taxon of grahamiae group taxa. The $S$. mexicana group is defined by a single preocular; three supralabials contacting eye $\left(4^{\text {th }}, 5^{\text {th }}\right.$ and $\left.6^{\text {th }}\right)$; maxillary teeth 14 to $15+3$; between 120 and 150 subcaudals; tail size in proportion to body size $(>29 \%)$; vertebral line at midbody one scale wide; and dorsolateral lines wider in the second third of body ( 3 scales wide). Our hypothesis of relationships among taxa within the mexicana and grahamiae groups differs from that proposed by Smith $(1938,1941)$.

Species in the S. grahamiae group share the following characters: divided preocular; supralabials, when contacting the eye, no more than two, or separate from the eye by suboculars (S. hexalepis subspp.); maxillary teeth $<13+3$; less than 120 subcaudals; tail size in proportion to body size $(<29 \%)$; vertebral line at midbody three scale wide, very rarely narrow in some specimens of $S$. intermedia; and dorsolateral lines narrow along body ( 2 or less scales wide).

The polytypic taxon Salvadora hexalepis, with four subspecies, was not recovered as a monophyletic clade. In our phylogeny, $S$. h. klauberi and $S$. $h$. virgultea are sister taxa, and S. grahamiae is sister to these two subspecies. Both subspecies of $S$. hexalepis are distributed in the westernmost part of the distributional range of the genus. Salvadora h. mojavensis is a sister taxon of $S$. $h$. hexalepis and both are sister taxa with $S$. deserticola, all of which are distributed in southeastern California, southern Nevada and southwestern Arizona. Both clades mentioned above are parapatric, one in the extreme west, and the other more inland to the east. The previous molecular phylogeny by Hernández-Jiménez et al. (2019) did not include all the subspecies of $S$. hexalepis, therefore it is not possible to compare our results at this level. Nevertheless, the $S$. hexalepis group is the sister group of $S$. deserticola under both hypotheses. 
Hartweg (1940) was curious about the relationship between S. intermedia and S. bairdi, as well as the relationship of these two species with $S$. lineata. In our phylogeny, these three taxa form a monophyletic sister group to $S$. gymnorhachis, though in the previous molecular phylogeny (Hernández-Jiménez et al. 2019), S. gymnorhachis is the sister taxon of $S$. intermedia, and $S$. bairdi appears as a sister taxon of S. grahamiae.

Smith (1938) suggested that $S$. bairdi and S. grahamiae are closely related, if considering several characters of cephalic squamation. Our results show these two taxa in different clades of the $S$. grahamiae group. Nevertheless, S. bairdi is more closely related to $S$. lineata as suggested by Schmidt (1940).

The clade formed by $S$. grahamiae and the subspecies of $S$. hexalepis and $S$. deserticola is characterized by taxa that have the vertebral line wider on the first third of the body (up to 5 scales) and usually with 9 supralabials, with at least one in contact with the eye. Schmidt (1940) proposed that the population of $S$. grahamiae from western Texas was most closely related to $S$. $h$. hexalepis from Arizona and may represent an undescribed taxon. We examined specimens from both regions and found no significant differences between them.

We conclude that the genus Salvadora is composed of 9 species, one of them polytypic (S. hexalepis with four subspecies). We support the suggestion of Davis \& Dixon (1957) that S. i. richardi is not a valid taxon and, therefore, no subspecies are recognized for this taxon.

Owing to the lack of diagnostic characters, and the confusion regarding the type locality, we conclude that $S$. bogerti (Smith 1941) is a junior synonym of $S$. bairdi. Due to morphological differences (see above under $S$. grahamiae) and the phylogenetic position of the two subspecies of $S$. grahamiae (see Fig. 2), we elevate these subspecies to the status of species, a conclusion that is supported by our preliminary molecular data and an unpublished thesis by Lannutti (2000).

Regarding Salvadora hexalepis and its subspecies, our morphological data indicate this taxon is nonmonophyletic; however, our preliminary molecular data and the placement of these taxa in Fig. 1 do not agree. We will refrain from suggesting any taxonomic change until more evidence has been published.

This is the first phylogenetic study of the snake genus Salvadora that includes all described taxa. We confirm the existence of two subclades corresponding with the two groups within the genus, a southern mexicana group and a northern grahamiae group. The monophyly of Salvadora is supported by several morphological synapomorphies. This genus is part of the Old Northern biogeographic element of Savage (1982), having its southern distribution limit in western Guatemala, but its greatest diversification is associated with the North American deserts. The majority of the taxa are part of the S. grahamiae group or the northern clade of Salvadora. Clarification of the relationship of Salvadora with the genus Leptodrymus will require additional molecular information.

Prior to our study, there were other incomplete molecular phylogenies that did not include all the taxa described, at the level of species and subspecies or employ the widespread geographic sampling of each taxon. The phylogeny and revision of the alpha taxonomy of the group, that we present here, represents the first hypothesis that includes all the taxa described in the group and a detailed revision of its alpha taxonomy throughout its entire distributional range, and provides an extra line of evidence for understanding the taxonomic situation of the genus Salvadora. The evidence from morphological phylogeny analyses corroborates most of the clades in our hypothesis based on previously published molecular data. We think that it is necessary to complement this information at the molecular level with a more extensive sampling that includes several populations and all the taxa described in the group. 


\section{Acknowledgments}

We would like to thank the late C.M. Bogert in particular for his contributions to the understanding of the genus Salvadora and for his legacy to Mexican herpetology. Prior to his death, he gave JAC copious unpublished notes on the genus Salvadora. This paper constitutes partial fulfillment of the requirements of Carlos A. Hernández-Jiménez as a doctoral student in the Posgrado en Ciencias Biológicas of the Universidad Nacional Autónoma de México and this publication is part of his doctoral dissertation. We thank Marisol Montellano, Livia León, and Jesus Sigala for their comments on a previous version of the manuscript. We thank Chris Grünwald, Rubén Carbajal, Adam Clause, Jorge Valdez and the 'colección herpetológica' of the Universidad Autónoma de Baja California for the specimen photographs as well as Carlos Montiel and Maritza Chavez for the help with the edition of the illustrations. We are especially grateful to the AMNH and D. Frost, for their support through the Theodore Roosevelt Memorial Grant awarded to CHJ. We are grateful to C. Franklin and E. Smith for their help in the revision process. We thank Bianca Delfosse and Fernanda Maldonado for their help with the final version the manuscript. OFV thanks the authorities of the UNAM and UTA for their support. We are grateful to the following collections and their curators for the loan of specimens AMNH, ANSP, BYU, CAS, CM, FMNH, LACM, KU, MCZ, MSB, MVZ, ROM, SDSNH, TCWC, UCM, UF, UIMNH, UMMZ, UNM, UTA, UTEP. Collecting permits were issue by SEMANAT to OFV (permit FAUT-0015).

\section{Disclosure statement}

The authors declare that they have no potential conflicts of interest.

\section{Funding}

This work was supported by CONACYT under a grant (CONACYT No. 175,623) awarded to CHJ; by the UNAM under a grant (DGAPA) awarded to OFV; and by the AMNH (Theodore Roosevelt Memorial Grant) awarded to CHJ to help fund part of the field work.

\section{References}

Amaral A.D. 1927. Studies of Neotropical ophidian. VI. A new genus of snakes from Honduras. Bulletin of the Antivenin Institute of America 1: 28-29. https://doi.org/10.5962/bhl.title.117755

Baird S.F. \& Girard C. 1853. Catalogue of North American Reptiles in the Museum of the Smithsonian Institution. Part 1 Serpents. Smithsonian Institution, Washington D.C.

https://doi.org/10.5962/bhl.title.5513

Blanchard F.N. 1924. A key to the snakes of the United States, Canada and Lower California. Papers from the Michigan Academy of Science Arts and Letters 4: 1-115.

Bocourt M.F. 1890. Mission scientifique au Mexique dans l'Amérique centrale. Reptiles. 12: 697-732.

Bogert C.M. 1935. Salvadora grahamiae virgultea, a new subspecies of the patch-nosed snake. Bulletin of the Southern California Academy of Sciences 34: 88-94.

Bogert C.M. 1939a. A study of the genus Salvadora. The patch-nosed snakes. Publications of the University of California at Los Angeles, Biological Sciences 1: 177-236.

Bogert C.M. 1939b. Notes on snakes of the genus Salvadora with a redescription of a neglected Mexican species. Copeia 1939 (3): 140-147. https://doi.org/10.2307/1436808

Bogert C.M. 1945. Two additional races of the patch-nosed snake Salvadora hexalepis. American Museum Novitates 1285: 1-14. 
Bogert C.M. 1947. The status of the genus Leptodrymus Amaral, with comments on modifications of colubrid premaxillae. American Museum Novitates 1352: 1-14.

Chang V. \& Smith E.N. 2001. Fast Morphology GFC Version 1.0.

Cope E.D. 1861. Catalogue of the Colubridae in the Museum of the Academy of Natural Sciences of Philadelphia. Part 3. Proceedings of the Academy of Natural Sciences of Philadelphia 12: 553-566.

Cope E.D. 1866. On the Reptilia and Batrachia of the Sonoran Province of the Nearctic region. Proceedings of the Academy of Natural Sciences of Philadelphia 18: 300-314.

Cope E.D. 1875. Check-list of North American Batrachia and Reptilia: With a Systematic List of the Higher Groups, and an Essay on Geographical Distribution; Based on the Specimens Contained in the US National Museum (Vol. 1). US Government Printing Office, Washington.

https://doi.org/10.5962/bhl.title.11851

Cope E.D. 1895. The classification of the Ophidia. Transactions of the American Philosophical Society 18: 186-219. https://doi.org/10.2307/1005387

Davis W.B. \& Dixon J.R. 1957. Notes on Mexican snakes (Ophidia). The Southwestern Naturalist 2: 19-27. https://doi.org/10.2307/3669560

Duméril A.M., Bibron C.G. \& Duméril A. 1854. Erpétologie générale ou Histoire naturelle complète des Reptiles. Vol. 7 (partie 1). Librairie encyclopédique de Roret. Paris.

https://doi.org/10.5962/bhl.title.118790

Figueroa A., McKelvy A.D., Grismer L.L., Bell C.D. \& Lailvaux S.P. 2016. A species-level phylogeny of extant snakes with description of a new colubrid subfamily and genus. PloS ONE (9) 11: 1-31. https://doi.org/10.1371/journal.pone.0161070

Flores-Villela O. 1993. Herpetofauna Mexicana: lista anotada de las especies de anfibios y reptiles de México, cambios taxonómicos recientes, y nuevas especies. Carnegie Museum of Natural History Special Publications 17: 1-75. https://doi.org/10.5962/bhl.title.123676

Günther A. 1863. Third account of new species of snakes in the collection of the British Museum. Annals and Magazine of Natural History 12: 348-365. https://doi.org/10.1080/00222936308681536

Hartweg N. 1940. Description of Salvadora intermedia, new species, with remarks on the grahamiae group. Copeia 1940 (4): 256-259. https://doi.org/10.2307/1438583

Hernández-Jiménez C.A., Flores-Villela O. \& Campbell J.A. 2019. A new species of patch-nosed snake (Colubridae: Salvadora Baird and Girard, 1853) from Oaxaca, Mexico. Zootaxa 4564 (2): 588-600. https://doi.org/10.11646/zootaxa.4564.2.14

Jan G. \& Sordelli F. 1860. Iconographie générale des Ophidiens. 1. Livraison. J.B. Bailière et Fils, Paris. https://doi.org/10.5962/bhl.title.45246

Jenner R.A. 2004. Accepting partnership by submission? Morphological phylogenetics in a molecular millennium. Systematic Biology 53: 333-342. https://doi.org/10.1080/10635150490423962

Lannutti D.I. 2000. Morphological variation in Salvadora grahamiae and related taxa. MSc Thesis, University of Texas, El Paso, Texas, USA.

Pérez-Higareda G. \& Smith H.M. 1991. Ofiodiofauna de Veracruz: análisis taxonómico y zoogeográfico. Publicaciones Especiales, Instituto de Biología, Universidad Nacional Autónoma de México, México D.F. 
Pérez-Higareda G., López-Luna M.A. \& Smith H.M. 2007. Serpientes de la Región de los Tuxtlas, Veracruz, México: Guía de Identificación ilustrada. Instituto de Biología, Universidad Nacional Autónoma de México, México D.F.

Pyron R.A., Burbrink F.T., Colli G.R., Nieto-Montes de Oca A., Vitt L.J., Kuczynski C.A. \& Wiens J.J. 2011. The phylogeny of advanced snakes (Colubroidea), with discovery of a new subfamily and comparison of support methods for likelihood trees. Molecular Phylogenetics and Evolution 58: 329-334. https://doi.org/10.1016/j.ympev.2010.11.006

Pyron R.A., Burbrink F.T. \& Wiens J.J. 2013. A phylogeny and revised classification of Squamata, including 4161 species of lizards and snakes. BMC Evolutionary Biology 13 (1): 93.

https://doi.org/10.1186/1471-2148-13-93

QGIS Development Team. 2012. QGIS Geographic Information System. Open Source Geospatial Foundation Project. Accessible from http://qgis.osgeo.org/es/site/ [accessed Oct. 2015].

Sabaj-Pérez M.H. (ed.) 2016. Standard symbolic codes for institutional resource collections in herpetology and ichthyology: An online reference. Ver. 4.0 (28 June 2013).

Available from http://www.asih.org [accessed Jan. 2017].

Savage J.M. 1982. The enigma of the Central American herpetofauna: dispersals or vicariance? Annals of the Missouri Botanical Garden 69: 464-547. https://doi.org/10.2307/2399082

Schmidt K.P. 1940. Notes on Texan snakes of the genus Salvadora. Field Museum of Natural History Zoological Series 24: 143-150. https://doi.org/10.5962/bhl.title.3249

Smith E.N. \& Gutberlet R.L. 2001. Generalized frequency coding: a method of preparing polymorphic multistate characters for phylogenetic analysis. Systematic Biology 50: 156-169.

https://doi.org/10.1080/10635150151125815

Smith H.M. 1938. Notes of the snakes of the genus Salvadora. The University of Kansas Science Bulletin 25: 229-237. https://doi.org/10.5962/bhl.part.1701

Smith H.M. 1941. Further notes on Mexican snakes of the genus Salvadora. Smithsonian Miscellaneous Collections 99: 1-12.

Available from https://repository.si.edu/handle/10088/23709 [accessed 23 Jul. 2021].

Smith H.M. \& Taylor E.H. 1950. Type localities of Mexican reptiles and amphibians. The University of Kansas Science Bulletin 33: 313-380.

Smith N.D. \& Turner A.H. 2005. Morphology's role in phylogeny reconstruction: perspectives from paleontology. Systematic Biology 54 (1): 166-173. https://doi.org/10.1080/10635150590906000

Stejneger L. 1902. The reptiles of the Huachuca Mountains, Arizona. Proceedings of the United States National Museum 25: 149-158. https://doi.org/10.5479/si.00963801.1282.149

Stuart L.C. 1932. Studies on Neotropical Colubrinae, I: The taxonomic status of the genus Drymobius Fitzinger. Occasional Papers of the Museum of Zoology, University of Michigan 236: 1-16.

Swofford D.L. 2002. PAUP* Phylogenetic analysis using parsimony (*and other methods), ver. 4.0a147. Sinauer Associates, Sunderland.

Thiele K. 1993. The holy grail of the perfect character: the cladistic treatment of morphometric data. Cladistics 9: 275-304. https://doi.org/10.1111/j.1096-0031.1993.tb00226.x

Tonini J.F.R., Beard K.H., Ferreira R.B., Jetz W. \& Pyron R.A. 2016. Fully-sampled phylogenies of squamates reveal evolutionary patterns in threat status. Biological Conservation 204: 23-31.

https://doi.org/10.1016/j.biocon.2016.03.039 
Wallach V., Williams K.L. \& Boundy J. 2014. Snakes of the World: a Catalogue of Living and Extinct Species. CRC Press, Boca Raton, Florida. https://doi.org/10.1201/b16901

Wiens J.J. 1995. Polymorphic characters in phylogenetic systematics. Systematic Biology 44: 482-500. https://doi.org/10.1093/sysbio/44.4.482

Wiens J.J. 2004. The role of morphological data in phylogeny reconstruction. Systematic Biology 53 (4): 653-661. https://doi.org/10.1080/10635150490472959

Wilkinson M. 1995. A comparison of two methods of character construction. Cladistics 11: 297-308. https://doi.org/10.1016/0748-3007(95)90017-9

Zaher H., Murphy R.W., Arredondo J.C., Graboski R., Machado-Filho P.R., Mahlow K. \& Grazziotin F.G. 2019. Large-scale molecular phylogeny, morphology, divergence-time estimation, and the fossil record of advanced caenophidian snakes (Squamata: Serpentes). PloS ONE 14 (5): e0217959.

https://doi.org/10.1371/journal.pone.0216148

Zheng Y. \& Wiens J.J. 2016. Combining phylogenomic and supermatrix approaches, and a timecalibrated phylogeny for squamate reptiles (lizards and snakes) based on 52 genes and 4162 species. Molecular Phylogenetics and Evolution 94: 537-547. https://doi.org/10.1016/j.ympev.2015.10.009

Manuscript received: 18 November 2020

Manuscript accepted: 21 June 2021

Published on: 25 August 2021

Topic editor: Rudy C.A.M. Jocqué

Desk editor: Kristiaan Hoedemakers

Printed versions of all papers are also deposited in the libraries of the institutes that are members of the EJT consortium: Muséum national d'histoire naturelle, Paris, France; Meise Botanic Garden, Belgium; Royal Museum for Central Africa, Tervuren, Belgium; Royal Belgian Institute of Natural Sciences, Brussels, Belgium; Natural History Museum of Denmark, Copenhagen, Denmark; Naturalis Biodiversity Center, Leiden, the Netherlands; Museo Nacional de Ciencias Naturales-CSIC, Madrid, Spain; Real Jardín Botánico de Madrid CSIC, Spain; Zoological Research Museum Alexander Koenig, Bonn, Germany; National Museum, Prague, Czech Republic.

Supp. file 1. Specimens and character matrix used for phylogenetic reconstruction. https://doi.org/10.5852/ejt.2021.764.1473.4895 